\title{
1 When killers become thieves: trogocytosed PD-1 inhibits NK cells in cancer
}

2 Mohammed S. Hasim ${ }^{1,2}$, Marie Marotel ${ }^{1,2}$, Jonathan J. Hodgins ${ }^{1,2,3}$, Elisabetta Vulpis ${ }^{4}$, Han-Yun

3 Shih $^{5}$, Amit Scheer ${ }^{3}$, Olivia MacMillan ${ }^{1,2,3}$, Fernando G. Alonso ${ }^{1}$, Kelly P. Burke ${ }^{6,7}$, David P.

4 Cook $^{1}$, Maria Teresa Petrucci ${ }^{8}$, Angela Santoni ${ }^{4,9}$, Padraic G. Fallon ${ }^{10}$, Arlene H. Sharpe ${ }^{11,12}$,

5 Giuseppe Sciumè ${ }^{4}$, Andre Veillette ${ }^{13,14,15}$, Alessandra Zingoni ${ }^{4}$, Arleigh McCurdy ${ }^{1,16}$, Michele

6 Ardolino $0^{1,2,3, *}$

7

8 1: Cancer Therapeutics Program, Ottawa Hospital Research Institute, Ottawa, ON

9 2: CI3, University of Ottawa, Ottawa, ON

10 3: Department of Biochemistry, Microbiology and Immunology, University of Ottawa, Ottawa,

\section{$11 \mathrm{ON}$}

12 4: Department of Molecular Medicine, Sapienza University of Rome, Laboratory affiliated to

13 Istituto Pasteur Italia - Fondazione Cenci-Bolognetti, Rome, Italy

14 5: Neuro-Immune Regulome Unit, National Eye Institute, NIH, Bethesda, MD

15 6: Department of Medical Oncology, Dana Farber Cancer Institute, Boston, MA

16 7: Harvard Medical School, Boston, MA

17 8: Department of Cellular Biotechnology and Hematology, "Sapienza" University of Rome, Rome,

18 Italy

19 9: IRCCS Neuromed, Pozzilli, Italy

20 10: School of Medicine, Trinity Biomedical Sciences Institute, Trinity College Dublin, Ireland

21 11: Department of Immunology, Blavatnik Institute, Harvard Medical School, Boston, MA

22 12: Evergrande Center for Immunologic Diseases, Harvard Medical School and Brigham and

23 Women's Hospital, Boston, MA 
24 13: Laboratory of Molecular Oncology, Institut de recherches cliniques de Montréal, Montréal,

25 Québec, Canada

26 14: Department of Medicine, University of Montréal, Montréal, Québec, Canada

27 15: Department of Medicine, McGill University, Montréal, Québec, Canada

28 16: Division of Hematology, Department of Medicine, University of Ottawa, Ottawa, ON

29

$30 *$ Correspondence:

31 Michele Ardolino

32501 Smyth Road, Cancer Center, 3-328, Ottawa, ON, K1H 8M2

33 m.ardolino@uottawa.ca

34 Tel: +1-613-737-8899 ext 77257 


\section{Once sentence summary:}

36 Natural Killer cells are inhibited by PD-1 acquired from the surface of tumor cells via trogocytosis.

\section{Abstract:}

39 Leucocytes often perform trogocytosis, the process by which cells acquire parts of the plasma

40 membrane from interacting cells. Accumulating evidence indicates that trogocytosis modulates

41 immune responses, but the underlying molecular mechanisms are unclear. Here, using two mouse

42 models of leukemia, we found that cytotoxic lymphocytes perform trogocytosis at high rates with

43 tumor cells. While performing trogocytosis, both Natural Killer and $\mathrm{CD}^{+} \mathrm{T}$ cells acquire the

44 checkpoint receptor PD-1 from leukemia cells. In vitro and in vivo investigation revealed that

45 PD-1 protein found on the surface of Natural Killer cells, rather than being endogenously

46 expressed, was derived entirely from leukemia cells. Mechanistically, SLAM receptors were

47 essential for PD-1 trogocytosis. PD-1 acquired via trogocytosis actively suppressed anti-tumor

48 immunity, as revealed by the positive outcome of PD-1 blockade in PD-1-deficient mice. PD-1

49 trogocytosis was corroborated in patients with clonal plasma cell disorders, where Natural Killer

50 cells that stained for PD-1 also stained for tumor cell markers. Our results, in addition to shedding

51 light on a previously unappreciated mechanism underlying the presence of PD-1 on Natural Killer

52 and cytotoxic $\mathrm{T}$ cells, reveal the immune-regulatory effect of membrane transfer occurring when

53 immune cells contact tumor cells. 


\section{Introduction:}

55 During trogocytosis immune cells acquire parts of the membrane of cells they interact with $(1,2)$.

56 First characterized in $\alpha \beta$-T cells (3-8), it later became clear that virtually all immune cells perform

57 trogocytosis $(7,9-16)$. This intercellular transfer of membranes results in the acquisition of proteins

58 that would otherwise not be endogenously expressed by the cell performing trogocytosis, as in the

59 case of NK cells that acquire viral proteins from infected cells $(17,18)$, or cancer antigens from

60 tumor cells (19). Proteins transferred via trogocytosis are functional and influence the response of

61 the accepting cell $(11,16,18,20-24)$. The pathophysiological relevance of trogocytosis is

62 underscored by the high extent that immune cells perform it in the context of infections $(25,26)$,

63 autoimmune diseases (27), and cancer (23, 28, 29). Natural Killer (NK) cells are important

64 mediators of the response against intracellular pathogens and tumors (30-32) and have been

65 amongst the first immune cells shown to perform trogocytosis (10-12). Trogocytosis has been

66 reported to contribute to the negative regulation of NK cell responses in different contexts. For

67 example, acquisition of m157 or NKG2D ligands results in sustained and unproductive

68 crosslinking of activating receptors leading to NK cell anergy $(18,33,34)$, but also promotes NK

69 fratricide $(34,35)$. On the other hand, acquisition of $\mathrm{MHC}$ molecules from target cells engaged

70 Ly49 receptors in cis, sustaining inhibitory signaling that dampened NK cell activation (11).

71 Finally, trogocytosis of HLA-G from cancer cells resulted in the generation of NK cells with

72 suppressive properties (36).

73

74 We recently reported that NK cells are suppressed by the checkpoint receptor PD-1 and contribute

75 to the therapeutic efficacy of PD-1/L1 blockade in mouse models of cancer (37). These results,

76 corroborated by others (38-43), were at least partially confuted by findings that murine and human 
77 NK cells fail to endogenously express $P d c d 1$ mRNA or PD-1 protein (44). In light of our results

78 indicating that PD-1 is found on the surface of NK cells, and considering the high trogocytosis

79 activity of NK cells, we propose that NK cells acquire PD-1 directly from tumor cells. Mechanistic

80 experiments corroborated our hypothesis and revealed that SLAM receptors were essential for

81 PD-1 trogocytosis. Functionally, trogocytosed PD-1 suppressed NK cell mediated cancer

82 immunosurveillance. Finally, analysis of NK cells in patients with clonal plasma cell disorders

83 suggests that PD-1 trogocytosis occurs in cancer patients. Altogether, our data shed light on a new

84 mechanism that regulates NK cell function via acquisition of PD-1 from tumor cells.

86 Materials and Methods.

87 Mice and in vivo procedures.

88 Mice were maintained at the University of Ottawa. Pdcdl knockout mice

89 (B6.Cg-Pdcd1tm1.1Shr/J)(45) were purchased from The Jackson Laboratory and crossed with

90 C57BL/6J mice purchased from The Jackson Laboratory to obtain $P d c d 1$ heterozygous mice.

91 Heterozygous mice were bred to obtain $\mathrm{Pdcd} \mathrm{I}^{+/+}$and $\mathrm{Pdcd1} \mathrm{I}^{-/-}$littermates. $\mathrm{Ncr} \mathrm{I}^{+/ \mathrm{Cre}}$ mice (46) were

92 kindly gifted by Dr. Vivier (INSERM, Marseille, France) and crossed with $C d 274^{f l f l}$ mice (47),

93 kindly gifted by Dr. Fallon (Trinity College, Dublin, Ireland). Mice were then crossed with

$94 P d c d 1^{-/}$mice. $C d 274^{-/}$mice (48) were obtained from Dr. Sharpe (Harvard Medical School,

95 Boston, MA). SLAM-ko mice (49) were donated by Dr. Veillette (Institut de recherches cliniques

96 de Montréal, Montréal, QC). Itgal1 $^{-/}$mice (50) were purchased from The Jackson Laboratory.

$97 \mathrm{Klrk1}^{-/-}$mice (51) and B6 Cd45.1 mice were kindly gifted by Dr. Raulet (University of California,

98 Berkeley, Berkeley, CA). NCG mice were purchased from Charles Rivers Laboratories. For all 
99 experiments, sex-matched (both males and females) and age-matched (7 to 18 weeks old) mice 100 were used.

101

102 For subcutaneous injections, tumor cells were resuspended in $100 \mu 1$ PBS and injected in the left

103 flank. Tumors were collected when tumor volume was approximately $300 \mathrm{~mm}^{3}$. In some 104 experiments, $0.5 \times 10^{6}$ tumor cells were resuspended in $100 \mu 1$ Growth Factor Reduced Matrigel 105 (BD) and injected in both the left and right flank of the same mouse.

107 Tumor outgrowth of parental or PD-1-deficient RMA-S-Pdll cells was assessed in $P d c d 1^{-/}$or

108 NCG mice injected with $0.1 \times 10^{6}$ tumor cells resuspended in $100 \mu$ l Matrigel.

109

110 For immunotherapy experiments, $0.5 \times 10^{6}$ tumor cells were resuspended in $100 \mu 1$ Matrigel mixed

111 with $20 \mu \mathrm{g}$ of anti-PD-1 (RMP1-14) or control antibody (1-1) (both by Leinco). In some 112 experiments, Fc-silent RMP-14 (52) was used.

114 When indicated, mice were depleted of NK cells with i.p. injection of $200 \mu \mathrm{g}$ of NKR-P1C 115 antibody (PK136, Leinco).

\section{Cell lines.}

118 All cell lines were cultured at $37^{\circ} \mathrm{C}$ in a humidified atmosphere containing $5 \% \mathrm{CO}_{2}$ and maintained 119 in RPMI culture medium containing $100 \mathrm{U} / \mathrm{ml}$ penicillin, $100 \mu \mathrm{g} / \mathrm{ml}$ streptomycin, $0.2 \mathrm{mg} / \mathrm{ml}$ 120 glutamine, $10 \mu \mathrm{g} / \mathrm{ml}$ gentamycin sulfate, $20 \mathrm{mM}$ HEPES, and 5\% FCS. Cell line identity was 121 confirmed by flow cytometry when possible, and cells were regularly tested for mycoplasma. 


\section{Ex vivo experiments.}

124 Murine splenic NK cells were isolated using the EasySep ${ }^{\mathrm{TM}}$ Mouse NK Cell Isolation Kit

125 (StemCell Technologies). In all experiments with isolated NK cells, $1000 \mathrm{U} / \mathrm{mL}$ rhIL-2 (NIH BRB

126 Preclinical Repository) was added to the culture medium. In most co-culture experiments NK cells

127 were labelled with Cell Trace Violet proliferation dye (BD Bioscience) and tumor cells with CFSE

128 (Biolegend), or vice-versa. 100,000 NK cells were co-cultured with tumor cells at a 1:1 ratio in 24

129 well plates in a final volume of $1 \mathrm{~mL}$. When whole spleens were used, 200,000 splenocytes were 130 co-cultured with tumor cells at a 2:1 ratio in 6 well plates, in a final volume of $3 \mathrm{ml}$.

132 In ex vivo cytokine stimulation experiments, isolated splenic NK cells were cultured with $10 \mathrm{ng} / \mathrm{ml}$

133 or 100ng/ml of IL-15 (Peprotech), 1,000U/ml IL-2, 100ng/ml IL-5 (Peprotech), 100 ng/ml IL-6

134 (Peprotech), 20ng/ml IL-12 (Peprotech) + 100 ng/ml IL-18 (Leinco), 10ng/ml TGF- $\beta 1$ 135 (Peprotech), 1,000U/ml Type I IFN (PBL Assay) or 25nM of the glucocorticoid Corticosterone 136 (Sigma) for 3 days.

138 For transwell experiments $(0.4 \mu \mathrm{m}$ filter, Millipore $)$, co-culture was set up in 6-well plates with a 139 final volume of $3 \mathrm{~mL}$.

141 In sup transfer experiments, RMA cells were seeded at 200,000 cells/ml and cultured for 3 days. 142 Conditioned media was collected, centrifuged, filtered, diluted 1:1 with fresh media and added to $143 \quad$ NK cells for 24 hrs. 
145 For membrane dye transfer experiments, NK cells were labelled with CFSE and RMA cells with 146 CellVue Claret FarRed (Sigma-Aldrich). 10,000 NK cells were then co-cultured with RMA cells

147 at a 1:10 ratio in 96-well V-bottom plates with a final volume of $100 \mu \mathrm{L}$.

148

149 In experiments where ATP production was pharmacologically blocked, NK cells were pre-treated 150 with $50 \mathrm{mM}$ of Sodium Azide (Sigma) for $2 \mathrm{hrs}$ or with $13 \mu \mathrm{M}$ of Antimycin-A (Sigma) for $1 \mathrm{hr}$, 151 washed and then incubated with RMA cells for one hour.

153 In experiments where PD-L1 was blocked, $5 \mu \mathrm{g}$ of PD-L1 blocking antibody clone 10F.9G2 (or 154 isotype control) was added to the co-culture.

155

156 In experiments where PD-1 was blocked in vitro, tumor cells were incubated with $5 \mu \mathrm{g}$ of

157 RMP1-14, Fc-silent RMP1-14 or control isotype for 20 minutes, then NK cells were added to the 158 culture. After 2 days, additional $5 \mu \mathrm{g}$ of antibodies were added to the co-culture and cells were 159 harvested and analyzed after 24 hrs. To check PD-1 saturation, an aliquot of co-culture or tumor 160 cell alone was stained with directly conjugated RMP1-14 or a non-competing PD-1 antibody 161 (29F.1A12).

\section{Flow cytometry.}

164 When needed, tumors were excised from mice, cut in pieces, resuspended in serum-free media, 165 and dissociated using a gentle MACS dissociator (Miltenyi). Following dissociation, the single 166 cell suspension was passed through a $40 \mu \mathrm{m}$ filter and cells were washed and resuspended in PBS

167 for staining. Spleens were harvested, gently dissociated through a $40 \mu \mathrm{m}$ filter, washed, and red 
168 blood cells were lysed using ACK buffer (Sigma), then washed and resuspended in PBS for 169 staining.

171 The cellular preparation was stained with the Zombie NIR Fixable Viability Dye (BioLegend) for

17220 mins in PBS to label dead cells. Cells were then washed with flow buffer (PBS $+0.5 \%$ BSA)

173 and incubated for 20 minutes with purified rat anti-mouse CD16/CD32 (Clone 2.4G2) (BD

174 Biosciences) to block Fc $\gamma$ RII/III receptors, followed by washing in flow buffer, and then incubated

175 for a further 20 minutes with primary specific antibodies. Cells were washed and resuspended in

176 flow buffer for sample acquisition or fixed in BD Cytofix/Cytoperm and acquired within 7 days.

177 Flow cytometry was performed using an LSRFortessa (BD) or a Celesta (BD), and data were

178 analyzed with FlowJo software (Tree Star Inc.)

179

180 Antibodies.

181 For experiments with murine cells, the following antibodies were used: $i$ ) from BD Biosciences:

182 anti-CD3e (clone 145-2C11); anti-CD8a (clone 53-6.7); anti-CD11b (clone M1/70); anti-CD11c

183 (clone HL3); anti-CD45.2 (clone 104); anti-CD49b (clone DX5); anti-CD69 (clone H1.2F3); anti-

184 Ly6G (clone 1A8); anti-NKR-P1C (clone PK136); anti-Sca-1 (clone D7); ii) from Biolegend: anti-

185 CD4 (clone RM4-5); anti-CD19 (clone 6D5); anti-TCRvß12 (clone MR11-1); anti-Thy-1.1 (clone

186 OX-7); anti-F4/80 (clone BM8); anti-Ly6c (clone HK1.4); anti-NKp46 (clone 29A1.4); anti-PD-

1871 (clone 29F.1A12); anti-PD-L1 (clone 10F.9G2); rat IgG2a isotype control; and mouse-IgG1

188 isotype control; iii) from Abcam: anti-CD45.1 (clone A20). 
190 For experiments with MM patients, the following antibodies were used: anti-CD3 (clone SK7), 191 anti-CD7 (clone M-T701), anti-CD16 (clone 3G8), anti-CD38 (clone HIT2), anti CD45 (clone

192 HI30), anti-CD56 (clone NCAM16.2), anti-CD138 (clone MI15) and anti-PD1 (clone EH12.1), all

193 from BD Biosciences.

195 Generation of cell line variants.

196 RMA, and C1498 cells were transduced with the retroviral expression vector 197 MSCV-IRES-Thy1.1-DEST (Addgene, 17442), by spin infection ( $800 \mathrm{x} \mathrm{g}$ for 2 hours at $37^{\circ} \mathrm{C}$ ) 198 with $8 \mu \mathrm{g} / \mathrm{ml}$ polybrene, and Thy $1.1+$ cells were sorted.

200 Single-guide RNA (sgRNA) targeting the first exon of the Pdcdl gene (sequence:

201 TGTGGGTCCGGCAGGTACCC) was cloned into the LentiCRISPR lentiviral backbone vector

202 (Addgene 52961), also containing the $\operatorname{Cas} 9$ gene. Lentiviral expression vectors were generated by 203 transfecting $293 \mathrm{~T}$ cells with $2 \mu \mathrm{g}$ vector with $2 \mu \mathrm{g}$ packaging plus polymerase-encoding plasmids 204 using Lipofectamine 2000. Virus-containing supernatants were used to transduce RMA-Thy1.1 205 cells by spin infection and PD-1 negative cells were sorted.

207 C1498-PD-1+ cells were obtained by sorting PD-1+ C1498 parental cells.

208

209 Generation of RMA-S-Pdl1 cells was previously described(37).

211 All engineered cells were regularly assessed for phenotype maintenance by flow cytometry. 


\section{ATAC-seq.}

214 Genomic snapshots were generated using IGV software (Broad Institute) using data available on

215 GEO: GSE77695(53) and GEO: GSE145299(54).

\section{Analysis of patients.}

218 BM aspirates were obtained from patients with clonal plasma cell disorder enrolled at the Ottawa

219 Hospital Research Institute and at the Division of Hematology (“Sapienza” University of Rome).

220 BM samples were lysed using a buffer composed of $1.5 \mathrm{M} \mathrm{NH}_{4} \mathrm{Cl}, 100 \mathrm{mM} \mathrm{NaHCO}_{3}$, and $10 \mathrm{mM}$

221 EDTA and then stained as described above.

222

\section{Statistical analysis.}

224 Differences in tumor growth curves were analyzed with a Two-way ANOVA. Comparison 225 between two groups were performed with Student's t-test (two tailed, paired or unpaired).

226 Comparison between three groups were performed with ANOVA. $\mathrm{p}<0.05$ was considered a 227 statistically significant difference.

\section{Study approvals.}

230 Mouse studies were reviewed and approved by Animal Care Veterinary Services at the University

231 of Ottawa in accordance with the guidelines of Canadian Institutes of Health Research. For human

232 studies, informed and written consent in accordance with the Declaration of Helsinki was obtained 233 from all patients, and approval was obtained from the Ethics Committee of the Sapienza University 234 of Rome (RIF.CE: 5191) or of The Ottawa Hospital (REB 20180221-02H). 


\section{Results:}

\section{Natural Killer cells acquire PD-1 from tumor cells.}

238 Consistent with what has been previously been reported $(37,44)$ murine NK cells stimulated ex

239 vivo with a panel of inflammatory mediators failed to upregulate PD-1 at the protein level (Fig.

240 S1). Lack of PD-1 induction was in line with epigenetic analysis of the $P d c d 1$ locus, which was

241 not accessible in splenic NK cells, either before or after cytokine stimulation, in sharp contrast

242 with the promoter of another checkpoint receptor (Tigit) in NK cells, or Pdcdl locus in CD8 ${ }^{+} \mathrm{T}$

243 cells (Fig. S2).

245 Considering the conflicting evidence regarding PD-1 expression on NK cells $(37,43,44)$ we

246 hypothesized that rather than endogenously expressing the protein, NK cells acquired PD-1 from

247 other cells. To test this hypothesis, we initially used RMA cells, which derive from transformation

248 of murine T cells (55), express high levels of PD-1 (Fig. 1A, in red), and were used extensively in

249 our previous study (37). We generated RMA cells expressing the syngeneic marker Thy-1.1 (not

250 expressed by C57BL/6 mice, which express the Thy-1.2 allelic variant) and targeted PD-1 with

251 CRISPR/Cas9 (RMA-Pdcd1 ${ }^{-/}$Thy1.1) (Fig. 1A, in blue and purple, respectively). We then

252 co-cultured tumor cells with splenocytes from $P d c d 1^{+/+}$or $P d c d 1^{-/-}$littermates with RMA cells

253 expressing PD-1 or not. In the absence of tumor cells, immune cells did not stain for PD-1 or

254 Thy-1.1. In sharp contrast, NK, T and B cells from both $P d c d 1^{+/+}$and $P d c d 1^{-/}$mice stained

255 positively for PD-1 when incubated with RMA cells, but not RMA-Pdcd1 ${ }^{-/}$cells (Fig. 1B),

256 indicating that PD-1 was not endogenously expressed by innate and adaptive lymphocytes, but

257 acquired from tumor cells in these settings. Consistent results were obtained by using NK cells

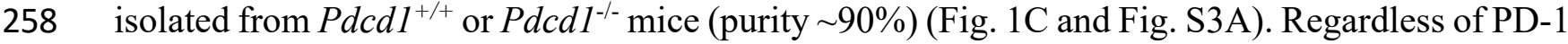


expression on tumor cells, Thy-1.1 was detected in abundance on the surface of immune cells (Fig. suggesting that the two molecules were transferred to NK cells as part of a unique phenomenon.

262 To determine if other proteins endogenously expressed by RMA cells were acquired by NK cells,

263 we co-cultured CD45.1-expressing NK cells with RMA cells (which express CD45.2). In addition

264 to PD-1 and Thy-1.1, NK cells also acquired TCRvß12 and CD45.2 (Fig. S4), although the staining was weaker than for PD-1 and Thy-1.1. These data indicate that when interacting with RMA cells, NK cells acquire several proteins they would not endogenously express.

To expand on these results, we next employed C1498 cells, an often-used model of leukemia(5658). A fraction of C1498 cells ( $~ 5 \%)$ endogenously expressed PD-1 in culture (Fig. 2A). We sorted PD $-1^{+} \mathrm{C} 1498$ cells, confirmed that they stably expressed PD-1 upon 2 weeks in culture (Fig. 2B),

271 and then incubated them with splenocytes from $P d c d 1^{+/+}$or $P d c d 1^{-/}$littermates. In accordance 272 with the results obtained with RMA cells, both NK cells and CD8 ${ }^{+} \mathrm{T}$ cells from $\mathrm{Pdcdl^{-- }}$ mice 273 acquired PD-1 when incubated with C1498 cells, and more so if tumor cells had higher PD-1

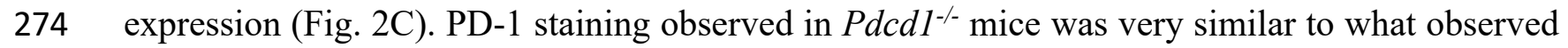

275 in the $P d c d 1^{+/+}$littermate controls, suggesting that even in the C1498 model, the most PD-1 was

276 not endogenously expressed by immune cells, but rather came from the tumor cells. Similar 277 experiments were repeated using purified NK cells from $P d c d 1^{-/}$NK cells. After 24 hours, NK 278 cells incubated with PD-1+C1498 cells stained positively for PD-1 (Fig. 2D). PD-1 staining was 279 further increased at 72 hours, when we also observed a shift in NK cells incubated with C1498 280 parental cells (Fig. 2D). Taken together, these data show that NK cells and CD8 T cells acquire 281 PD-1 from leukemia tumor cell lines in vitro. 


\section{Trogocytosis is responsible for intercellular transfer of PD-1 from tumor to NK cells.}

284 Once we established that NK cells acquired PD-1 from tumor cells, we next investigated whether

285 trogocytosis was responsible for PD-1 transfer. Cell-cell contact is required for trogocytosis.

286 Consistent with our hypothesis that PD-1 is acquired by trogocytosis, $P d c d 1^{-/-} \mathrm{NK}$ cells cultured

287 in transwell with tumor cells (where physical interaction between the two cell types is precluded)

288 failed to stain for PD-1 and Thy-1.1 (Fig. 3A). Further, NK cells incubated with supernatant

289 conditioned by RMA cells failed to stain for PD-1 (Fig. 3B). These experiments reveal that cell-cell

290 contact is required for PD-1 acquisition by NK cells, and suggest that soluble or exosomal PD-1

291 is not responsible for PD-1 transfer.

293 Blocking ATP synthesis is known to interfere with trogocytosis.(10) Consistent with the idea that

294 PD-1 is acquired via trogocytosis by NK cells, pretreatment of NK cells with sodium azide or 295 Antimycin-A, which both prevent ATP synthesis, resulted in a strong reduction of PD-1 and 296 Thy-1.1 acquisition (Fig. 3C).

298 Transfer of proteins via trogocytosis is accompanied by transfer of membrane lipids. PD-1 transfer 299 was coupled with acquisition of lipids from tumor cells, as revealed by experiments wherein NK 300 cells were co-cultured with RMA cells previously labelled with Cell-Vue, a dye that intercalates 301 in the lipid regions of the cellular membrane (Fig. 3D). Not only did NK cells become robustly 302 positive for the dye, but PD-1 staining was more abundantly detected on NK cells that also 303 acquired lipids from tumor cells (Fig. 3D). These experiments indicate that PD-1, together with 
other proteins, is acquired contextually with transfer of whole membrane fragments, which is consistent with trogocytosis.

SLAM receptors are required for NK cells to trogocytose PD-1 from tumor cells.

Acquisition of proteins from donor cells can be facilitated by receptor-ligand engagement, a process known as trans-endocytosis, which NK cells are known to mediate (59). In culture, NK cells fail to express PD-L2 but express PD-L1 (Fig. 4A and (60)), which could therefore serve as

311 a ligand for trans-endocytosis-driven PD-1 acquisition. However, a saturating dose of PD-L1

312 blocking antibody did not reduce PD-1 acquisition (Fig. 4B-C) as we would expect if

313 trans-endocytosis was involved. Similar results were obtained blocking PD-1 on RMA cells with

314 an antibody that prevents binding of PD-L1. Despite the antibodies saturated PD-1 on the 315 membrane of RMA cells (Fig. S5A), PD-1 and Thy-1.1 were still effectively transferred to NK 316 cells (Fig. S5B). These experiments not only suggest that PD-1/PD-L1 binding is not required for

317 PD-1 transfer, but also imply that Fc-receptor engagement by PD-1 antibodies does not facilitate 318 trogocytosis (61). Finally, we sought genetic corroboration using PD-L1-deficient NK cells from 319 two different mouse strains: a full body PD-L1 knock-out $\left(C d 274^{-/}\right)(48)$ and an NK cell specific 320 PD-L1 knockout $\left(N c r 1^{+/ C r e}\right.$ x $\left.C d 274^{f l f l}\right)(47)$ that we crossed with PD-1-deficient mice $\left(P d c d 1^{-/-}\right.$ $\left.321 \mathrm{Ncrl}^{+/ \mathrm{Cre}} \mathrm{Cd} 274^{f l / f l}\right)$. PD-L1 deficient NK cells acquired PD-1 and Thy-1.1 at levels similar to NK 322 cells isolated from PD-L1 expressing controls (Fig. 4D-E). PD-L1 was also dispensable for PD-1 323 and Thy-1.1 acquisition in $\mathrm{CD}^{+} \mathrm{T}$ cells and B cells (Fig. S6).

325 SLAM receptors are important mediators of cell-cell interactions between hematopoietic cells and 326 are abundantly expressed not only by NK cells but also by T and B cells (62). Given the broad 
327 expression of SLAM family members, their importance in regulating the activation of different

328 immune cells and considering that PD-1 was trogocytosed by both innate and adaptive

329 lymphocytes, we hypothesized that SLAM receptors promoted PD-1 trogocytosis. To test this

330 hypothesis, we cultured splenocytes from mice where the whole SLAM locus was deleted (49) with

331 tumor cells and then assessed PD-1 and Thy-1.1 staining on NK, T and B cells. Consistent with

332 our hypothesis, NK cells from SLAM-deficient mice failed to acquire PD-1 from RMA cells (Fig.

333 4F-G). Not only was PD-1 acquisition abolished, but more broadly, SLAM-deficient NK cells

334 failed to perform trogocytosis with tumor cells, as revealed by lack of Thy-1.1 transfer (Fig. 4F-G).

335 In addition to NK cells, SLAM-deficient T and B cells also displayed reduced trogocytosis (Fig.

336 S7), confirming that SLAM receptors are key mediators for trogocytosis between immune cells

337 and leukemia cells.

339 Given the importance of SLAM receptors in mediating cell-cell interactions, we analyzed if 340 deficiency in other adhesion molecules also interfered with trogocytosis. LFA-1 is a key adhesion

341 molecule, but NK cells lacking expression of CD11a,(50) a subunit of LFA-1, did not present a

342 deficit in PD-1 or Thy-1.1 acquisition (Fig. 4H). Similar results were also observed analyzing

$343 \mathrm{CD}^{+} \mathrm{T}$ and $\mathrm{B}$ cells (Fig. S8). NKG2D, an activating receptor ubiquitously expressed by NK

344 cells,(63) was also not involved in mediating trogocytosis between NK and RMA cells (Fig. S9).

345 Taken together, these results indicate that SLAM receptors, but not other adhesion molecules or 346 activating receptors, mediate PD-1 trogocytosis from tumor to immune cells. 
349 Next, we performed in vivo studies to determine if intratumoral NK cells trogocytosed PD-1. We

350 injected $P d c d 1^{+/+}$or $P d c d 1^{-/-}$littermates with RMA or RMA-Pdcd1 $1^{-/}$cells, both expressing

351 Thy-1.1, and when tumors reached $\sim 300 \mathrm{~mm}^{3}$ we analyzed PD-1 staining on intratumoral

352 lymphocytes. In all cohorts of mice, NK cells infiltrating the tumors stained intensely for Thy-1.1

353 (Fig. 5A-D, Y axis), showing that trogocytosis occurred in vivo. Strikingly, high levels of PD-1

354 were detected on the surface of NK cells only when tumor cells expressed PD-1, not only in

$355 P d c d 1^{+/+}$, but also in $P d c d 1^{-/}$mice (Fig. 5A and C vs B and D). These data show not only that

356 PD-1 is acquired by tumor infiltrating NK cells, but also that trogocytosis is the major mechanism

357 leading to PD-1 presence on the surface of NK cells in the RMA model. Consistent with what was

358 observed on NK cells, $\mathrm{CD}^{+} \mathrm{T}$ cells from $\mathrm{Pdcd1} 1^{-/}$mice also acquired Thy-1.1 and PD-1 from

359 tumor cells (Fig. 5C). As expected, PD-1 staining in $\mathrm{CD}^{+} \mathrm{T}$ cells was also observed in $\mathrm{Pdcd1^{+/+ }}$

360 mice injected with PD-1-deficient RMA cells, confirming that $\mathrm{CD}^{+} \mathrm{T}$ cells endogenously

361 expressed PD-1 in vivo. In our previous study, we reported that PD-1 staining was higher on

362 activated NK cells (37). Analysis of NK and T cells from $P d c d 1^{-/-}$mice infiltrating RMA tumors

363 confirmed that PD- $1^{+} \mathrm{NK}$ and $\mathrm{T}$ cells also stained more brightly for activation markers such as

364 Sca-1 and CD69 (Fig. 5E), supporting the idea that the NK cells that are activated by the encounter

365 with tumor cells are also the ones more susceptible to acquiring PD-1 and therefore being inhibited

366 by it.

368 To further support our hypothesis that PD-1 was trogocytosed by NK cells in the tumor 369 microenvironment, we injected $P d c d 1^{-/-}$mice with RMA or RMA-Pdcd1/- cells in either flank. As

370 previously reported (37), splenic NK cells failed to stain for PD-1 (Fig. 5F). Consistent with what

371 is described in Fig. 5A-D, NK cells in both tumors acquired Thy-1.1 from tumor cells, but only 
372 NK cells in PD-1 expressing tumors also stained for PD-1 (Fig. 5F). Taken together, these results

373 highlight how activated NK cells perform trogocytosis and acquire PD-1 in the tumor

374 microenvironment in vivo.

375

376

PD-1 acquired via trogocytosis inhibits NK cell responses against cancer.

377 Once we established that NK cells trogocytose PD-1 in vivo, we sought to determine if 378 trogocytosed PD-1 suppressed anti-tumor immunity. For these studies, rather than using RMA 379 cells (which are resistant to both $\mathrm{T}$ and $\mathrm{NK}$ cell responses $(37,55,56,64)$ ) we took advantage of 380 RMA-S-Pdll cells we previously generated (37). Similar to RMA, these cells express high levels 381 of PD-1, but differently than RMA, they lack MHC class I expression and are therefore susceptible 382 to NK-mediated control (37). Using CRISPR/Cas9, we generated an RMA-S-Pdl1 variant lacking 383 PD-1 expression (Fig. 6A). When injected in $P d c d 1^{-/}$mice, where the only source of PD-1 on NK

384 cells are tumor cells, we observed a dramatic deceleration in outgrowth of tumor cells lacking 385 PD-1 expression (Fig. 6B). However, lack of PD-1 did not delay cell growth in vitro, nor it 386 prevented RMA-S-Pdl1-Pdcd1/- cells from growing tumors in immunodeficient mice (Fig. 6C).

387 These data indicate that, rather than having cell intrinsic growth defects, PD-1-deficient tumor 388 cells have reduced capacity of forming ectopic tumors as they fail to inhibit NK cells via PD-1 389 transfer.

391 Using the RMA-S-Pdl1 model, we previously showed that PD-1 blockade rescued the ability of 392 NK cells to control tumor growth in vivo (37). Considering that PD-1 expression in tumor cells 393 promoted in vivo growth in a cell extrinsic fashion, we reasoned that the therapeutic effect of PD-1 394 blockade should also be observed in $P d c d 1^{-/}$mice. In accordance with our hypothesis, when we 
treated PD-1-deficient mice injected with RMA-S-Pdll cells with a PD-1 blocking antibody (RMP1-14) we observed a dramatic reduction in tumor outgrowth (Fig. 6D). On the other hand,

397 when we injected PD-1-deficient mice with PD-1 deficient RMA-S-Pdll cells, PD-1 blockade had 398 no therapeutic effect (Fig. 6E).

400 To confirm that NK cells, and not other components of the immune response, were inhibited by 401 tumor derived PD-1, we injected RMA-S-Pdll cells in mice where NK cells were depleted using 402 a monoclonal antibody (PK136) and treated the mice with PD-1 blockade. NK cell depletion was 403 sufficient to abolish the therapeutic effect of the blocking antibody, whereas PD-1 blockade 404 delayed tumor outgrowth in the control group (Fig. 6F). Corroboration of these results came from 405 experiments where PD-1 antibodies failed in immunocompromised mice (Fig. 6G). Moreover, the 406 similar in vivo growth of tumor cells in immunocompromised mice (Fig. 6G) excluded a tumor 407 cell intrinsic effect of PD-1 blocking antibodies.

409 Finally, to rule out that the therapeutic effect of PD-1 antibodies was due to Antibody-Dependent 410 Cellular Cytotoxicity (ADCC) potentially mediated by NK cells against cancer cells coated with

411 PD-1 antibodies, we employed an engineered version of anti-PD-1 that lacks the ability to bind to 412 Fc-receptors (Fc-silent RMP1-14) (52). Treatment with Fc-silent PD-1 antibodies delayed the 413 outgrowth of PD-1 expressing tumors (Fig. 6H), indicating that the therapeutic effect of PD-1

414 antibodies in $P d c d 1^{-/-}$mice was not due to ADCC. Taken together, these results indicate that 415 trogocytosed PD-1 inhibits the anti-tumor activity of NK cells, which can be rescued by PD-1 416 blocking antibodies. 
418 Identification of an NK cells population in multiple myeloma patients staining for tumor cell markers and PD-1.

420 Finally, to determine if NK cells acquire PD-1 from tumor cells in cancer patients, we analyzed

421 PD-1 staining in NK cells from the bone marrow (BM) of patients with clonal plasma cell disorders

422 (Table 1 details patients' information). Pathological analysis showed that of the 28 patients

423 analyzed, 21 were diagnosed with multiple myeloma (MM), 3 with monoclonal gammopathy of

424 undetermined significance (MGUS), 3 with smoldering myeloma, and 1 with solitary

425 plasmacytoma. For these studies, we relied on CD138, a protein frequently expressed by clonal

426 plasma cells but not by NK cells (65), as a surrogate trogocytosis marker. Flow cytometry analysis

427 confirmed the presence in several patients of a high scattering CD138 ${ }^{+}$population (Fig. S10), that

428 we identified as clonal plasma cells. In support of our gating strategy, patients diagnosed with MM

429 presented a higher CD138 ${ }^{+}$frequency than MGUS patients. NK cells were instead gated as low

430 scattering events, live, $\mathrm{CD} 3{ }^{-} \mathrm{CD} 56^{+} \mathrm{CD} 16^{+/-}$and in most samples $\mathrm{CD} 7$ was also used (Fig. S10). In

431 the vast majority of samples analyzed, high scattering-CD138 ${ }^{+}$cells expressed PD-1 (Sup. Fig.

432 10). Indication that NK cells performed trogocytosis came from analysis of BM aspirates where a

$433 \mathrm{CD} 138^{+} \mathrm{NK}$ cell population, in both $\mathrm{CD} 56^{\text {bright }} \mathrm{CD} 16^{-}$and $\mathrm{CD} 56^{\mathrm{dim}} \mathrm{CD} 16^{+} \mathrm{NK}$ cell subsets, was

434 identified (Fig. 7, in pink and green), corroborating the results obtained in murine models. Notably,

435 we found a sizeable and consistent (albeit often small) population of NK cells that stained for both

436 CD138 and PD-1 (Fig. 7, in green), supporting the idea that NK cells in patients with clonal plasma

437 cell disorders acquire PD-1 and cancer cell markers from tumor cells. 
439 In conclusion, this study identifies trogocytosis as a new mechanism by which PD-1 is acquired

440 from tumor cells. by NK and T cells. PD-1 trogocytosis strongly relies on SLAM receptors and

441 functionally suppresses the ability of NK cells to eliminate tumors in vivo.

443 Discussion.

444 The nature of PD-1 expression on NK cells remains fairly elusive, with contrasting 445 evidence indicating that PD-1 is either expressed on not expressed in NK cells (43, 44).

446 Considering the importance of PD-1 in suppressing the immune response to cancer (66), and given 447 the tremendous interest in the development of NK cell based cancer immunotherapies $(32,67)$, 448 understanding whether PD-1 directly inhibits NK cell function is of the utmost importance. We 449 recently reported that PD-1 suppresses NK cells in several mouse models of cancer (37), but 450 previously have not yet deciphered the mechanisms leading to PD-1 upregulation in murine NK 451 cells infiltrating lymphoma mouse models. The lack of PD-1 induction in NK cells following 452 several ex vivo stimulations, combined with the analysis of the $P d c d 1$ locus in resting and cytokine 453 stimulated NK cells, prompted us to hypothesize that PD-1 was not endogenously expressed by 454 NK cells but rather be derived from other sources. Several cellular processes have been shown to 455 be responsible for protein transfer. Amongst these processes, trogocytosis, the intercellular 456 exchange of whole membrane fragments, is highly performed by NK cells (10-12). Proteins 457 transferred via trogocytosis can have a substantial impact in immune function $(1,2)$. In cancer, 458 trogocytosis has been associated with reduced immune responses and with the failure of 459 immunotherapy. For example, a recent study highlighted how CAR T cells trogocytose antigens 460 from tumor cells and become susceptible to fratricide, greatly limiting the response to cellular 461 therapy (68). Trogocytosis triggered by Fc-receptors engaging therapeutic antibodies, performed 
462 by myeloid and NK cells, has been a major hurdle limiting the efficacy of monoclonal antibodies 463 against cancer antigens $(15,61,69-85)$. Despite such evidence and the immense interest in

464 elucidating mechanisms underlying resistance to PD-1 blockade, whether PD-1 is trogocytosed by

465 immune cells has been largely unexplored. Here we show that in some contexts trogocytosis is a 466 major mechanism by which PD-1 becomes localized on the surface of immune cells. This was true

467 not only for NK cells, but also for adaptive lymphocytes. PD-1 acquisition happened in a cell-cell 468 contact dependent fashion, contextualized within the transfer of other proteins and whole 469 membrane fragments and was strongly suppressed by ATP depletion, indicating that PD-1 was 470 trogocytosed by immune cells. Interestingly, PD-1 antibodies did not elicit PD-1 trogocytosis by

471 NK cells, suggesting that PD-1 could be acquired by NK cells even in the absence of Fc-receptor

472 engagement. Mechanistic studies using blocking antibodies and transgenic mice allowed us to 473 exclude a role for PD-L1, abundantly expressed by NK cells, in PD-1 acquisition, ruling out 474 trans-endocytosis as a mechanism of PD-1 transfer. On the other hand, receptors belonging to the 475 SLAM family proved to be essential for intercellular transfer of PD-1 from tumor to immune cells.

476 SLAM receptors are important regulators of immune function and ubiquitously expressed by NK 477 cells (62), but also by tumors of hematopoietic origin, including multiple myeloma (86). Our 478 finding that SLAMs promote the transfer of PD-1 from tumor to immune cells requires 479 consideration of trogocytosis as an important biological variable when designing mono -or 480 combination therapies targeting these receptors.

481 Trogocytosed PD-1 was functional and suppressed the anti-cancer activity of NK cells. The 482 in vivo studies performed here further expand on our previous findings that NK cells contribute to 483 the therapeutic efficacy of PD-1 blockade (37), and explain why checkpoint blockade relies on NK 484 cells despite their lack of PD-1 expression. 
While more translational studies are required to follow up on this mechanistic data, we successfully identified a subset of NK cells which stained for CD138 in the bone marrow of

487 patients with clonal plasma cell disorders. As CD138 is not expressed by NK cells, we relied on

488 CD138 staining to identify bone marrow NK cells that performed trogocytosis. Consistent with

489 our in vivo results, CD $138^{+} \mathrm{NK}$ cells also stained for PD-1, and flow cytometry and bioinformatic

490 analysis of a published dataset indicated that multiple myeloma cells can express PD-1 (87). Based

491 on our in vivo results, we propose that PD-1 expression, in addition to benefiting cancer cells with

492 intrinsic signaling (88), also promotes immune escape. In fact, tumor cells expressing PD-1 can 493 donate this powerful inhibitory receptor to activated immune cells when they are in direct contact.

494 PD-1 acquisition can however be therapeutically abrogated by checkpoint blockade, potentially

495 rescuing the ability of NK cells to promote anti-cancer immunity.

497 fraction of human NK cells that did not stain for CD138. These data are consistent with the idea 498 that human NK cells endogenously express PD-1, as recently corroborated in healthy donors and 499 patients undergoing hematopoietic stem cell transplantation (43). Endogenous expression of PD-1 500 does not exclude the possibility that immune cells also rely on trogocytosis to gain further PD-1

501 protein from neighbor cells. This notion is well supported by a recent study that identified 502 trogocytosing NK cells in a broad spectrum of hematopoietic malignancies (89). In accordance 503 with our data, NK cells labelled with tumor cell markers also stained for PD-1 (89). Whether 504 endogenously expressed by NK cells or acquired from cancer or other immune cells, several 505 reports, including the present one, have highlighted the importance of PD-1 in suppressing NK 506 cells $(37-43)$. 
Finally, in light of these results, it will be important for future immune-profiling efforts

based on transcriptomic analysis to take into account that proteins are acquired, sometimes at

509 surprisingly high levels, by immune cells in the tumor microenvironment. Pursuant to our previous

510 studies and given its known importance in suppressing anti-cancer responses we focused on PD-1;

511 however, it is conceivable that other proteins with immunomodulatory potential will be acquired

512 by NK and T cells while interacting with tumor cells. Further characterization of the mechanisms

513 underlying membrane transfer and identification of molecules transferred to immune cells is

514 required to elucidate how immune cells are regulated by checkpoint receptors, and other proteins,

515 in a transcription-independent fashion.

\section{Acknowledgment:}

518 We thank members of the Ardolino lab, Drs. Horan, Vanderhyden, Gray, Scott,

519 Bourgeois-Daigneault, Kissov and Piconese for critically reading the manuscript; Fernando Ortiz,

520 Drs. Tang, Stanford, Ito and the CHEO flow-core for support with flow-cytometry; the ACVS

521 facility at the University of Ottawa for support with animal studies. MA is supported by Ride for

522 Dad, CIHR and Myeloma Canada, HYS by the NIH intramural research programs, GS and AS by

523 AIRC, AZ by Sapienza University, PGF by Science Foundation Ireland, AHS by NIH (PO1 grant

524 56299). EV is supported by an AIRC fellowship. MM is the recipient of a CAAIF postdoctoral

525 fellowship. JJH and DC are recipients of a Frederick Banting and Charles Best Canada Graduate

526 Scholarships Doctoral Award from CIHR. We are thankful to Dr. Ravetch (Rockefeller

527 University) for providing us with Fc-silent PD-1 antibodies and to Dr. Raulet, for providing us

528 with mouse lines and continuous support. This manuscript is dedicated to the memory of Dr. Lucas

529 Horan, who loved science and the Bay. 
531 Authorship contributions.

532 Author contributions are detailed according to CRediT criteria.

\begin{tabular}{|c|c|c|c|c|c|c|c|c|c|c|}
\hline Author & Conceptualization & $\begin{array}{l}\text { Formal } \\
\text { analysis }\end{array}$ & $\begin{array}{l}\text { Funding } \\
\text { acquisition }\end{array}$ & Investigation & Methodology & Resources & Supervision & Visualization & $\begin{array}{c}\text { Writing } \\
- \\
\text { original } \\
\text { draft }\end{array}$ & $\begin{array}{c}\text { Writing } \\
\text { review - } \\
\& \\
\text { editing }\end{array}$ \\
\hline MSH & $\mathrm{X}$ & & & $\mathrm{X}$ & $\mathrm{X}$ & & & & & $\mathrm{X}$ \\
\hline MM & & $\mathrm{X}$ & & $\mathrm{X}$ & & & & & & $X$ \\
\hline JJH & & & & $\mathrm{X}$ & & & & & & $\mathrm{X}$ \\
\hline EV & & & & $\mathrm{X}$ & & & & & $\mathrm{X}$ & $\mathrm{X}$ \\
\hline HYS & $\mathrm{X}$ & $\mathrm{X}$ & $\mathrm{X}$ & & & & & $\mathrm{X}$ & & $\mathrm{X}$ \\
\hline AS & & & & $\mathrm{X}$ & & & & & & $\mathrm{X}$ \\
\hline OMM & & & & $\mathrm{X}$ & & & & & & $\mathrm{X}$ \\
\hline FGA & & & & $\mathrm{X}$ & & & & & & $\mathrm{X}$ \\
\hline KPB & & & & & & $\mathrm{X}$ & & & & $\mathrm{X}$ \\
\hline $\mathrm{DC}$ & & $\mathrm{X}$ & & & & & & & & $\mathrm{X}$ \\
\hline MTP & & & & & & $\mathrm{X}$ & & & & $\mathrm{X}$ \\
\hline AS & & & $\mathrm{X}$ & & & $\mathrm{X}$ & $\mathrm{X}$ & & & $\mathrm{X}$ \\
\hline PGF & & & & & & $X$ & & & & $X$ \\
\hline AS & & & & & & $\mathrm{X}$ & & & & $\mathrm{X}$ \\
\hline GS & $\mathrm{X}$ & $\mathrm{X}$ & $\mathrm{X}$ & & & & $\mathrm{X}$ & & & $\mathrm{X}$ \\
\hline $\mathrm{AV}$ & & & & & & $\mathrm{X}$ & & & & $\bar{X}$ \\
\hline $\mathrm{AZ}$ & $\mathrm{X}$ & & $\mathrm{X}$ & & & $\mathrm{X}$ & $\mathrm{X}$ & & & $\mathrm{X}$ \\
\hline $\mathrm{AMC}$ & $\mathrm{X}$ & & $X$ & & & $\mathrm{X}$ & & & & $\mathrm{X}$ \\
\hline MA & $\mathrm{X}$ & $\mathrm{X}$ & $\mathrm{X}$ & $\mathrm{X}$ & $\mathrm{X}$ & & $\mathrm{X}$ & $\mathrm{X}$ & $\mathrm{X}$ & $\mathrm{X}$ \\
\hline
\end{tabular}

534 Disclosure of conflicts of interests: MA received monetary compensation from Alloy

535 Therapeutics for consulting. MA is under a contract agreement to perform sponsored research with

536 Actym Therapeutics. Neither consulting nor sponsored research are related to the present article.

537 The other authors have declared that no conflict of interest exists.

\section{References:}

1. D. Hudrisier, E. Joly, What is trogocytosis and what is its purpose? Nat Immunol 4, 815 (2003).

2. A. Bettadapur, H. W. Miller, K. S. Ralston, Biting off what can be chewed: Trogocytosis in health, infection and disease. Infect Immun, (2020).

3. J. F. Huang et al., TCR-Mediated internalization of peptide-MHC complexes acquired by $\mathrm{T}$ cells. Science 286, 952-954 (1999).

4. I. Hwang et al., T cells can use either T cell receptor or CD28 receptors to absorb and internalize cell surface molecules derived from antigen-presenting cells. J Exp Med 191, 1137-1148 (2000). 
5. D. Hudrisier, J. Riond, H. Mazarguil, J. E. Gairin, E. Joly, Cutting edge: CTLs rapidly capture membrane fragments from target cells in a TCR signaling-dependent manner. J Immunol 166, 3645-3649 (2001).

6. D. Hudrisier, J. Riond, L. Garidou, C. Duthoit, E. Joly, T cell activation correlates with an increased proportion of antigen among the materials acquired from target cells. Eur J Immunol 35, 2284-2294 (2005).

7. D. Hudrisier, A. Aucher, A. L. Puaux, C. Bordier, E. Joly, Capture of target cell membrane components via trogocytosis is triggered by a selected set of surface molecules on $\mathrm{T}$ or $\mathrm{B}$

8. D. Hudrisier et al., Ligand binding but undetected functional response of FcR after their capture by T cells via trogocytosis. J Immunol 183, 6102-6113 (2009).

9. F. D. Batista, D. Iber, M. S. Neuberger, B cells acquire antigen from target cells after synapse formation. Nature 411, 489-494 (2001).

10. L. M. Carlin, K. Eleme, F. E. McCann, D. M. Davis, Intercellular transfer and supramolecular organization of human leukocyte antigen $C$ at inhibitory natural killer cell immune synapses (vol 194, pg 1507, 2001). Journal of Experimental Medicine 194, 1883 (2001).

11. A. Sjostrom et al., Acquisition of external major histocompatibility complex class I molecules by natural killer cells expressing inhibitory Ly49 receptors. J Exp Med 194, 15191530 (2001).

12. J. Tabiasco et al., Active trans-synaptic capture of membrane fragments by natural killer cells. Eur J Immunol 32, 1502-1508 (2002).

13. O. B. Herrera et al., A novel pathway of alloantigen presentation by dendritic cells. $J$ Immunol 173, 4828-4837 (2004).

14. A. Aucher, E. Magdeleine, E. Joly, D. Hudrisier, Capture of plasma membrane fragments from target cells by trogocytosis requires signaling in T cells but not in B cells. Blood 111, 5621-5628 (2008).

15. S. Daubeuf, M. A. Lindorfer, R. P. Taylor, E. Joly, D. Hudrisier, The direction of plasma membrane exchange between lymphocytes and accessory cells by trogocytosis is influenced by the nature of the accessory cell. J Immunol 184, 1897-1908 (2010).

16. K. Miyake et al., Trogocytosis of peptide-MHC class II complexes from dendritic cells confers antigen-presenting ability on basophils. Proc Natl Acad Sci U S A 114, 1111-1116 (2017).

17. J. Tabiasco et al., Acquisition of viral receptor by NK cells through immunological synapse. J Immunol 170, 5993-5998 (2003).

18. C. A. Miner, T. K. Giri, C. E. Meyer, M. Shabsovich, S. K. Tripathy, Acquisition of activation receptor ligand by trogocytosis renders NK cells hyporesponsive. J Immunol 194, 19451953 (2015).

19. N. Stern-Ginossar et al., Intercellular transfer of carcinoembryonic antigen from tumor cells to NK cells. J Immunol 179, 4424-4434 (2007).

20. D. M. Patel, P. Y. Arnold, G. A. White, J. P. Nardella, M. D. Mannie, Class II MHC/peptide complexes are released from APC and are acquired by $T$ cell responders during specific antigen recognition. J Immunol 163, 5201-5210 (1999). 
591 21. J. Zimmer, V. loannidis, W. Held, H-2D ligand expression by Ly49A+ natural killer (NK) cells precludes ligand uptake from environmental cells: implications for NK cell function. $J$ Exp Med 194, 1531-1539 (2001).

22. J. LeMaoult et al., Immune regulation by pretenders: cell-to-cell transfers of HLA-G make effector T cells act as regulatory cells. Blood 109, 2040-2048 (2007).

23. R. Brown et al., CD86+ or HLA-G+ can be transferred via trogocytosis from myeloma cells to T cells and are associated with poor prognosis. Blood 120, 2055-2063 (2012).

24. J. Reed, S. A. Wetzel, Trogocytosis-Mediated Intracellular Signaling in CD4(+) T Cells Drives TH2-Associated Effector Cytokine Production and Differentiation. J Immunol 202, 28732887 (2019).

25. U. Tomaru et al., Detection of virus-specific T cells and CD8+ T-cell epitopes by acquisition of peptide-HLA-GFP complexes: analysis of T-cell phenotype and function in chronic viral infections. Nat Med 9, 469-476 (2003).

26. K. Rosenits, S. J. Keppler, S. Vucikuja, P. Aichele, T cells acquire cell surface determinants of APC via in vivo trogocytosis during viral infections. Eur J Immunol 40, 3450-3457 (2010).

27. B. Haastert, R. J. Mellanby, S. M. Anderton, R. A. O'Connor, T cells at the site of autoimmune inflammation show increased potential for trogocytosis. PLoS One 8, e81404 (2013).

28. R. Brown et al., Trogocytosis generates acquired regulatory T cells adding further complexity to the dysfunctional immune response in multiple myeloma. Oncoimmunology 1, 1658-1660 (2012).

29. G. Eisenberg et al., Imprinting of lymphocytes with melanoma antigens acquired by trogocytosis facilitates identification of tumor-reactive T cells. J Immunol 190, 5856-5865 (2013).

30. E. Vivier et al., Innate or adaptive immunity? The example of natural killer cells. Science 331, 44-49 (2011).

31. A. Iannello, T. W. Thompson, M. Ardolino, A. Marcus, D. H. Raulet, Immunosurveillance and immunotherapy of tumors by innate immune cells. Current opinion in immunology 38, 52-58 (2015).

32. J. J. Hodgins, S. T. Khan, M. M. Park, R. C. Auer, M. Ardolino, Killers 2.0: NK cell therapies at the forefront of cancer control. J Clin Invest 129, 3499-3510 (2019).

33. P. Roda-Navarro, M. Vales-Gomez, S. E. Chisholm, H. T. Reyburn, Transfer of NKG2D and MICB at the cytotoxic NK cell immune synapse correlates with a reduction in NK cell cytotoxic function. Proc Natl Acad Sci U S A 103, 11258-11263 (2006).

34. F. E. McCann, P. Eissmann, B. Onfelt, R. Leung, D. M. Davis, The activating NKG2D ligand $\mathrm{MHC}$ class I-related chain A transfers from target cells to NK cells in a manner that allows functional consequences. J Immunol 178, 3418-3426 (2007).

35. K. Nakamura et al., Fratricide of natural killer cells dressed with tumor-derived NKG2D ligand. Proc Natl Acad Sci U S A 110, 9421-9426 (2013).

36. J. Caumartin et al., Trogocytosis-based generation of suppressive NK cells. Embo J 26, 1423-1433 (2007).

37. J. Hsu et al., Contribution of NK cells to immunotherapy mediated by PD-1/PD-L1 blockade. J Clin Invest 128, 4654-4668 (2018). 
38. D. M. Benson et al., The PD-1/PD-L1 axis modulates the natural killer cell versus multiple myeloma effect: a therapeutic target for CT-011, a novel monoclonal anti-PD-1 antibody. Blood 116, 2286-2294 (2010).

39. A. Beldi-Ferchiou et al., PD-1 mediates functional exhaustion of activated NK cells in patients with Kaposi sarcoma. Oncotarget 7, 72961-72977 (2016).

40. S. Pesce et al., Identification of a subset of human natural killer cells expressing high levels of programmed death 1: A phenotypic and functional characterization. J Allergy Clin Immunol 139, 335-346.e333 (2017).

41. Y. Liu et al., Increased expression of programmed cell death protein 1 on NK cells inhibits NK-cell-mediated anti-tumor function and indicates poor prognosis in digestive cancers. Oncogene 36, 6143-6153 (2017).

42. F. Vari et al., Immune evasion via PD-1/PD-L1 on NK cells and monocyte/macrophages is more prominent in Hodgkin lymphoma than DLBCL. Blood 131, 1809-1819 (2018).

43. Z. Davis et al., Low-density PD-1 expression on resting human natural killer cells is functional and upregulated after transplantation. Blood Advances 5, 1069-1080 (2021).

44. S. J. Judge et al., Minimal PD-1 expression in mouse and human NK cells under diverse conditions. J Clin Invest, (2020).

45. M. E. Keir, G. J. Freeman, A. H. Sharpe, PD-1 regulates self-reactive CD8+ T cell responses to antigen in lymph nodes and tissues. J Immunol 179, 5064-5070 (2007).

46. E. Narni-Mancinelli et al., Fate mapping analysis of lymphoid cells expressing the NKp46 cell surface receptor. Proc Natl Acad Sci U S A 108, 18324-18329 (2011).

47. C. Schwartz et al., ILC2s regulate adaptive Th2 cell functions via PD-L1 checkpoint control. Journal of Experimental Medicine 214, 2507-2521 (2017).

48. Y. E. Latchman et al., PD-L1-deficient mice show that PD-L1 on T cells, antigen-presenting cells, and host tissues negatively regulates T cells. Proc Natl Acad Sci U S A 101, 1069110696 (2004).

49. H. Guo et al., Deletion of Slam locus in mice reveals inhibitory role of SLAM family in NK cell responses regulated by cytokines and LFA-1. J Exp Med 213, 2187-2207 (2016).

50. Z. M. Ding et al., Relative contribution of LFA-1 and Mac-1 to neutrophil adhesion and migration. J Immunol 163, 5029-5038 (1999).

51. N. Guerra et al., NKG2D-deficient mice are defective in tumor surveillance in models of spontaneous malignancy. Immunity 28, 571-580 (2008).

52. R. Dahan et al., FcgammaRs Modulate the Anti-tumor Activity of Antibodies Targeting the PD-1/PD-L1 Axis. Cancer Cell 28, 285-295 (2015).

53. H. Y. Shih et al., Developmental Acquisition of Regulomes Underlies Innate Lymphoid Cell Functionality. Cell 165, 1120-1133 (2016).

54. G. Sciume et al., Rapid Enhancer Remodeling and Transcription Factor Repurposing Enable High Magnitude Gene Induction upon Acute Activation of NK Cells. Immunity 53, 745-758 e744 (2020).

55. K. Kärre, H. G. Ljunggren, G. Piontek, R. Kiessling, Selective rejection of H-2-deficient lymphoma variants suggests alternative immune defence strategy. Nature 319, 675-678 (1986). 
678 57. E. Curran et al., STING Pathway Activation Stimulates Potent Immunity against Acute Myeloid Leukemia. Cell Rep 15, 2357-2366 (2016).

680 58. M. Ruzicka et al., RIG-I-based immunotherapy enhances survival in preclinical AML models and sensitizes AML cells to checkpoint blockade. Leukemia 34, 1017-1026 (2020).

59. O. M. Anton et al., Trans-endocytosis of intact IL-15Ralpha-IL-15 complex from presenting cells into NK cells favors signaling for proliferation. Proc Natl Acad Sci U S A 117, 522-531 (2020).

60. W. Dong et al., The Mechanism of Anti-PD-L1 Antibody Efficacy against PD-L1-Negative Tumors Identifies NK Cells Expressing PD-L1 as a Cytolytic Effector. Cancer discovery 9, 1422-1437 (2019).

61. R. P. Taylor, M. A. Lindorfer, Fcy-receptor-mediated trogocytosis impacts mAb-based therapies: historical precedence and recent developments. Blood 125, 762-766 (2015).

62. N. Wu, A. Veillette, SLAM family receptors in normal immunity and immune pathologies. Current opinion in immunology 38, 45-51 (2016).

63. E. O. Long, H. S. Kim, D. Liu, M. E. Peterson, S. Rajagopalan, Controlling natural killer cell responses: integration of signals for activation and inhibition. Annu Rev Immunol 31, 227258 (2013).

64. H. G. Ljunggren, K. Kärre, Host resistance directed selectively against H-2-deficient lymphoma variants. Analysis of the mechanism. J Exp Med 162, 1745-1759 (1985).

65. E. A. Stadtmauer et al., Long-term safety and activity of NY-ESO-1 SPEAR T cells after autologous stem cell transplant for myeloma. Blood Adv 3, 2022-2034 (2019).

66. A. H. Sharpe, K. E. Pauken, The diverse functions of the PD1 inhibitory pathway. Nat Rev Immunol 18, 153-167 (2018).

67. J. S. Miller, L. L. Lanier, Natural Killer Cells in Cancer Immunotherapy. Annual Review of Cancer Biology 3, 77-103 (2019).

68. M. Hamieh et al., CAR T cell trogocytosis and cooperative killing regulate tumour antigen escape. Nature 568, 112-116 (2019).

69. A. D. Kennedy et al., Rituximab infusion promotes rapid complement depletion and acute CD20 loss in chronic lymphocytic leukemia. J Immunol 172, 3280-3288 (2004).

70. P. V. Beum, A. D. Kennedy, M. E. Williams, M. A. Lindorfer, R. P. Taylor, The shaving reaction: rituximab/CD20 complexes are removed from mantle cell lymphoma and chronic lymphocytic leukemia cells by THP-1 monocytes. J Immunol 176, 2600-2609 (2006).

71. Y. Li et al., Rituximab-CD20 complexes are shaved from Z138 mantle cell lymphoma cells in intravenous and subcutaneous SCID mouse models. J Immunol 179, 4263-4271 (2007).

72. P. V. Beum, D. A. Mack, A. W. Pawluczkowycz, M. A. Lindorfer, R. P. Taylor, Binding of rituximab, trastuzumab, cetuximab, or mAb T101 to cancer cells promotes trogocytosis mediated by THP-1 cells and monocytes. J Immunol 181, 8120-8132 (2008).

73. P. V. Beum, M. A. Lindorfer, R. P. Taylor, Within peripheral blood mononuclear cells, antibody-dependent cellular cytotoxicity of rituximab-opsonized Daudi cells is promoted by NK cells and inhibited by monocytes due to shaving. J Immunol 181, 2916-2924 (2008).

74. B. A. Nijmeijer et al., A mechanistic rationale for combining alemtuzumab and rituximab in the treatment of ALL. Blood 116, 5930-5940 (2010). 
75. G. Aue et al., Fractionated subcutaneous rituximab is well-tolerated and preserves CD20 expression on tumor cells in patients with chronic lymphocytic leukemia. Haematologica 95, 329-332 (2010).

76. T. Pham, P. Mero, J. W. Booth, Dynamics of macrophage trogocytosis of rituximab-coated B cells. PLoS One 6, e14498 (2011).

77. A. E. Pedersen, M. B. Jungersen, C. D. Pedersen, Monocytes mediate shaving of B-cellbound anti-CD20 antibodies. Immunology 133, 239-245 (2011).

78. P. V. Beum et al., Loss of CD20 and bound CD20 antibody from opsonized B cells occurs more rapidly because of trogocytosis mediated by Fc receptor-expressing effector cells than direct internalization by the B cells. J Immunol 187, 3438-3447 (2011).

79. P. Boross, J. H. Jansen, A. Pastula, C. E. van der Poel, J. H. Leusen, Both activating and inhibitory Fc gamma receptors mediate rituximab-induced trogocytosis of CD20 in mice. Immunology letters 143, 44-52 (2012).

80. J. D. Jones, B. J. Hamilton, W. F. Rigby, Rituximab mediates loss of CD19 on B cells in the absence of cell death. Arthritis and rheumatism 64, 3111-3118 (2012).

81. F. J. Beurskens et al., Exhaustion of cytotoxic effector systems may limit monoclonal antibody-based immunotherapy in cancer patients. J Immunol 188, 3532-3541 (2012).

82. N. A. Baig et al., Induced resistance to ofatumumab-mediated cell clearance mechanisms, including complement-dependent cytotoxicity, in chronic lymphocytic leukemia. J Immunol 192, 1620-1629 (2014).

83. C. S. Zent et al., Chemoimmunotherapy for relapsed/refractory and progressive 17p13deleted chronic lymphocytic leukemia (CLL) combining pentostatin, alemtuzumab, and low-dose rituximab is effective and tolerable and limits loss of CD20 expression by circulating CLL cells. Am J Hematol 89, 757-765 (2014).

84. M. Carlsten et al., Checkpoint Inhibition of KIR2D with the Monoclonal Antibody IPH2101 Induces Contraction and Hyporesponsiveness of NK Cells in Patients with Myeloma. Clinical cancer research : an official journal of the American Association for Cancer Research 22, 5211-5222 (2016).

85. J. Krejcik et al., Monocytes and Granulocytes Reduce CD38 Expression Levels on Myeloma Cells in Patients Treated with Daratumumab. Clinical cancer research : an official journal of the American Association for Cancer Research 23, 7498-7511 (2017).

86. S. V. Radhakrishnan, N. Bhardwaj, T. Luetkens, D. Atanackovic, Novel anti-myeloma immunotherapies targeting the SLAM family of receptors. Oncoimmunology 6, e1308618e1308618 (2017).

87. Y. C. Cohen et al., Identification of resistance pathways and therapeutic targets in relapsed multiple myeloma patients through single-cell sequencing. Nat Med, (2021).

88. H. Zha et al., Non-canonical PD-1 signaling in cancer and its potential implications in clinic. Journal for ImmunoTherapy of Cancer 9, e001230 (2021).

89. D. N. Vo et al., Dissecting the NK Cell Population in Hematological Cancers Confirms the Presence of Tumor Cells and Their Impact on NK Population Function. Vaccines (Basel) 8, (2020). 


\section{Table 1}

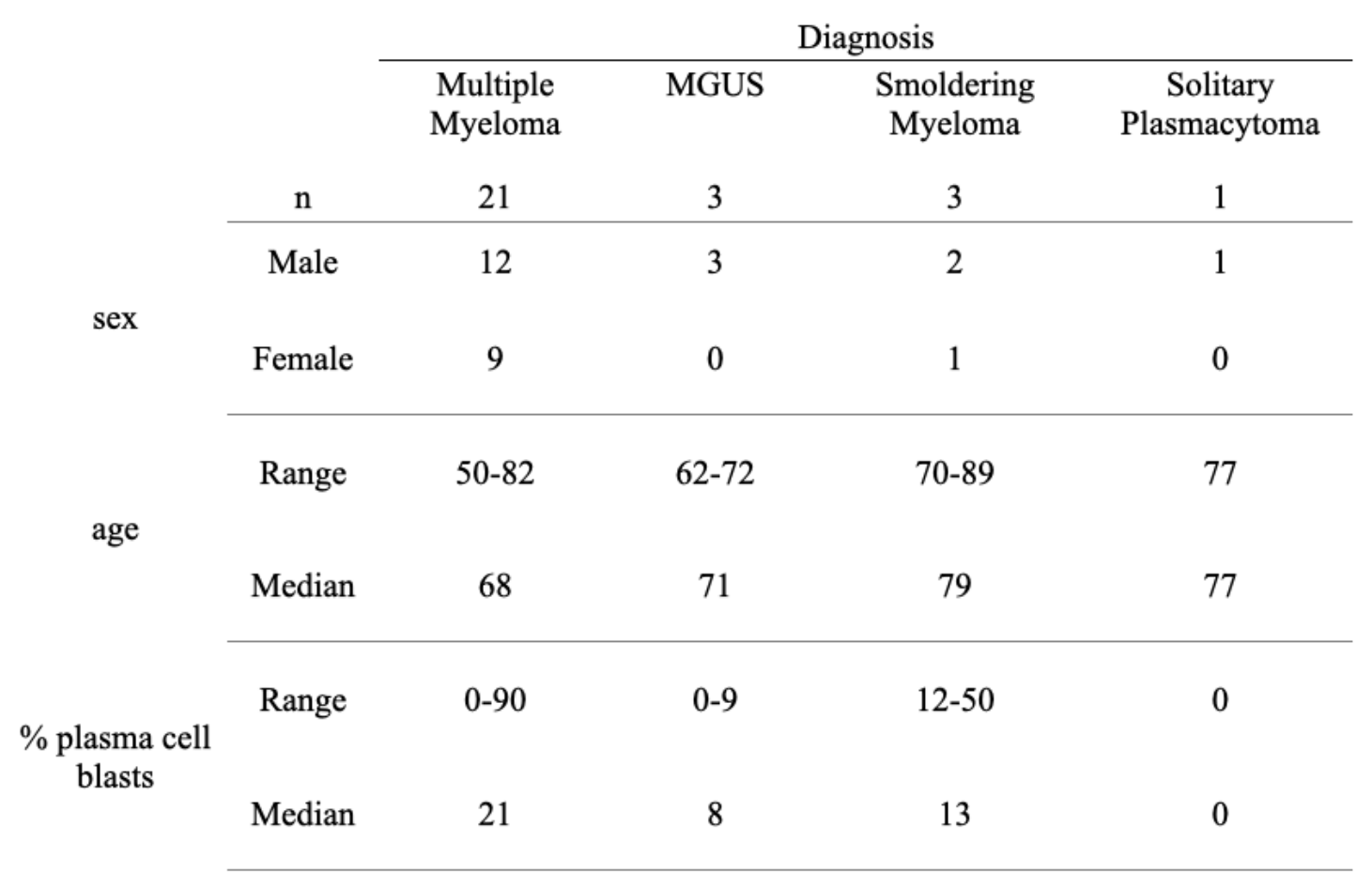

765

766 Figure Legends:

767 Figure 1: Lymphocytes acquire PD-1 and Thy.1-1 from RMA cancer cells. (A) RMA cells (red)

768 were transduced with a retroviral vector encoding Thy-1.1 to generate RMA-Thy1.1 (blue) and then

769 PD-1 was knocked-out by CRISPR/Cas9 to generate RMA-Pdcd1-/-Thy1.1 (purple). A representative

770 flow-cytometry staining depicting PD-1 and Thy-1.1 expression is shown. (B) Splenocytes from

$771 P d c d 1^{+/+}$or $P d c d 1^{-/}$littermates were incubated with RMA-Thy1.1 or RMA-Pdcd1 $1^{--}$Thy1.1. After 3

772 days, cells were stained with Thy1.1 and PD-1 antibodies. NK cells were gated as

773 singlets/live-NK $1.1^{+} \mathrm{NKp} 46^{+} \mathrm{DX} 5^{+}$events. $\mathrm{CD} 8^{+} \mathrm{T}$ cells were gated as singlets/live-CD ${ }^{+} \mathrm{CD} 8^{+}$events,

774 B cells as singlets/live-CD19 ${ }^{+}$. The experiment depicted is representative of three performed with

775 similar results. (C) NK cells isolated from $P d c d 1^{+/+}$or $P d c d 1^{-/-}$littermates were incubated with

776 RMA-Thy1.1 or RMA-Pdcd1/-Thy1.1. After 3 days, cells were stained with Thy1.1 and PD-1

777 antibodies. The experiment depicted is representative of fifteen performed with similar results. 
Figure 2: NK cells and T cells acquire PD-1 from C1498 cancer cells. (A) C1498 cells were stained with PD-1 antibody or isotype control. PD-1+ cells (in blue) were flow-sorted and after 2 weeks in culture stained for PD-1, alongside with parental C1498 cells (B). (C) Splenocytes from $P d c d 1^{+/+}$or

787 similar results. isolated from a $\mathrm{Pdcd1} 1^{-/}$mouse were co-cultured for $24 \mathrm{hrs}$ with RMA cells or with media conditioned

794 for three days by RMA cells, then stained for PD-1 and Thy-1.1. The experiment depicted is 795 representative of three performed with similar results. (C) Splenic NK cells isolated from a $P d c d 1^{-/}$ mouse were pre-treated with Sodium Azide or Antimycin-A, then co-cultured for one hour with RMA

797 cells and stained for PD-1 and Thy-1.1. Three independent experiments are plotted. Statistical analysis with one-way ANOVA with repeated measurements. (D) NK cells were incubated with RMA cells and right respectively. 
Figure 4: SLAM receptors are essential for trogocytosis. (A) Splenic NK cells isolated from a $P d c d 1^{-/}$mouse were cultured for 3 days and then PD-L2 and PD-L1 expression was analyzed by

804 flow-cytometry. Representative of three experiments performed with similar results. (B-C) NK cells were incubated with RMA cells in the presence of a PD-L1 blocking antibody or an isotype control for

$80624 \mathrm{hrs}$, before being stained for PD-1 and PD-L1. As additional controls, NK cells were: $i$ ) co-cultured 807 with RMA without adding any antibody; or ii) cultured alone without adding tumor cells. The 808 experiment depicted is representative of three performed. (D-E) NK cells were isolated from the spleen 809 of $\mathrm{Pdcd1} 1^{-/} \mathrm{Ncrl}^{+/ \mathrm{Cre}} \mathrm{Cd} 274^{f l / f l}$ (D) or $\mathrm{Cd} 274^{-/-}$(E) mice and co-cultured for three days with RMA or 810 C1498 tumor cells, when PD-1 and Thy-1.1 staining was assessed by flow cytometry. (F-G)

811 Splenocytes from SLAM-deficient mice or control littermates were co-cultured for three days with 812 RMA or C1498 cells. PD-1 and Thy-1.1 staining on NK cells was then assessed by flow cytometry.

813 The experiment depicted is representative of 3 performed. In G, the frequency of NK cells staining for 814 PD-1 or Thy-1.1 in WT or SLAM-deficient mice analyzed in the three experiments is plotted. 815 Statistical analysis with two-tailed unpaired Student's t-test. ***: $\mathrm{p}<0.001$. (H) Splenocytes from 816 LFA-1-deficient or WT mice were co-cultured for three days with RMA cells. Representative of 3 817 experiments performed.

819 Figure 5: Intratumoral lymphocytes acquire PD-1 from tumor cells. (A-D) $P d c d 1^{+/+}$or $P d c d 1^{-/-}$

820 mice were injected with RMA or RMA-Pdcd1 $1^{-/}$tumors. PD-1 and Thy-1.1 staining was assessed by 821 flow-cytometry on tumor infiltrating NK and T cells (gated as in Fig. 1B and 1C, respectively). The 822 experiment shown is representative of four performed with similar results. (E) Expression of Sca1 and 823 CD69 was analyzed on $P d c d 1^{-/} \mathrm{NK}$ and T cells infiltrating RMA tumors, by gating on Thy-1.1-PD-1 ${ }^{-}$ 
824 (gray), Thy-1.1 ${ }^{+} \mathrm{PD}-1^{-}$(red) or Thy- $1.1^{+} \mathrm{PD}-1^{+}$(blue) cells. The mouse depicted is the same depicted in

825 2C. (F) RMA or RMA-Thy.1-1 cells were injected in either flank of a Pdcd1 ${ }^{-/}$mouse. PD-1 and

826 Thy.1-1 staining was analyzed in intratumoral or splenic NK cells. The experiment depicted is

827 representative of two performed.

829 Figure 6: PD-1 blockade is effective in $\boldsymbol{P d c d 1}^{-/}$mice when NK cells are present and tumor cells

831 analyzed by flow cytometry. (B-H) In all experiments, the indicated cell lines were injected resuspended in Matrigel, alone or mixed with different PD-1 blocking or control antibody. Tumor growth was assessed over time and data were analyzed with 2-way ANOVA. (B) n=6/group, the

834 experiment depicted is representative of two performed with similar results. (C) $n=6 /$ group, the experiment depicted is representative of two performed with similar results. (D) $n=4 /$ group, the experiment depicted is representative of two performed with similar results. (E) n=6/group, the 837 experiment depicted is representative of three performed with similar results. $(\mathrm{F}) \mathrm{n}=$ at least 5/group, 838 the experiment depicted is representative of two performed with similar results. $(G) n=5 /$ group, the 839 experiment depicted is representative of two performed with similar results. $(\mathrm{H}) \mathrm{n}=5 /$ group, the experiment depicted is representative of two performed with similar results. $*$ : $\mathrm{p}<0.05 ; * *: \mathrm{p}<0.01$;

843 Figure 7: NK cells co-stain for CD138 and PD-1 in the bone marrow of patients with clonal 844 plasma cell disorders. The bone marrow aspirates of 28 patients with clonal plasma cell disorders 845 were analyzed by flow cytometry. The frequency of NK cells staining for either, neither or both CD138 846 and PD-1 is depicted. 
SUPPLEMENTARY MATERIAL

848 Supplementary Figure 1: Inflammatory signals fail to induce PD-1 upregulation in purified NK

849 cells in vitro. Magnetically enriched NK cells from $P d c d 1^{+/+}$or $P d c d 1^{-/}$mice were cultured for $72 \mathrm{hrs}$

850 with the inflammatory mediators indicated in the figure. GC=glucocorticoid (Corticosterone). NK

851 cells from 3 mice/genotype where pooled. The experiment depicted is representative of 3 performed.

853 Supplementary Figure 2: The Pdcd1 locus is closed in resting NK cells. Genomic snapshots of 854 normalized ATAC-seq signals in NK cells, naïve and memory CD8+ T cells across Pdcd1 and Tigit 855 loci.

857 Supplementary Figure 3: PD-1 and Thy-1.1 are co-acquired by NK cells. NK cells isolated from 858 the spleens of $P d c d 1^{-/}$mice were co-cultured with RMA or RMA-Pdcd1 ${ }^{-/}$cells for three days. A and 859 B show the frequency of PD- $1^{+}$or Thy $-1.1^{+} \mathrm{NK}$ cells in the 14 mice analyzed in the 13 experiments 860 performed. In A and B Statistical analysis with ANOVA with Dunnet's multiple comparison test. In 861 (C) the correlation between PD- $1^{+}$and Thy- $1.1^{+} \mathrm{NK}$ cells is depicted. $95 \%$-confidence interval is also 862 showed, statistical analysis with Spearman correlation test.

864 Supplementary Figure 4: NK cells acquire at least four proteins they do not endogenously express from RMA cells. CD45.1+ NK cells were co-cultured with RMA cells for three days and then PD-1, Thy-1.1, CD45.2 and TCRv $\beta 12$ staining was analyzed by flow cytometry. Representative of three performed with similar results. 
870 Supplementary Figure 5: PD-1 antibodies do not affect or promote PD-1 trogocytosis by NK

871 cells. (A) Saturation of PD-1 sites on RMA cells was assessed by stained with the PD-1 antibody cells

872 that were previously co-incubated with anti-PD-1 or control isotype. (B) NK cells purified from

$873 P d c d 1^{-/}$mice were incubated with RMA cells in the presence of the indicated blocking antibody and

874 then stained for PD-1 and Thy-1.1. The experiment depicted is representative of three performed.

875

876 Supplementary Figure 6: PD-L1 is dispensable for PD-1 trogocytosis in NK, T and B cells.

$877 C d 274^{-/-}$or wild type splenocytes were cultured with tumor cells for 3 days before PD-1 and Thy-1.1

878 staining was assessed by flow cytometry. Representative of 3 mice/genotype analyzed.

Supplementary Figure 7: SLAM receptors are required for trogocytosis in $\mathrm{CDB}^{+} \mathrm{T}$ and $\mathrm{B}$ cells.

SLAM-ko or wild type splenocytes were cultured with tumor cells for three days. Representative

882 staining and cumulative analysis are depicted. Statistical analysis with two-tailed unpaired Student's t-test. $* * *: \mathrm{p}<0.001$

Supplementary Figure 8: LFA-1 is not necessary for trogocytosis in $\mathrm{CD8}^{+} \mathbf{T}$ and $\mathrm{B}$ cells. Itgal $1^{-/-}$or wild type splenocytes were cultured with tumor cells for three days when PD-1 and Thy-1.1 staining

887 was assessed on CD8+ T cells and B cells.

889 Supplementary Figure 9: NKG2D is not required for trogocytosis in NK cells. $K l r k 1^{-/}$or control

890 littermates NK cells were cultured with tumor cells for three days and then stained for PD-1 and

891 Thy-1.1. 
893 Supplementary Figure 10: the gating strategy for NK and T cell identification in the bone marrow of

894 patients with clonal plasma cell disorders is displayed. 
A available under aCC-BY-Ne 4.0 international license.

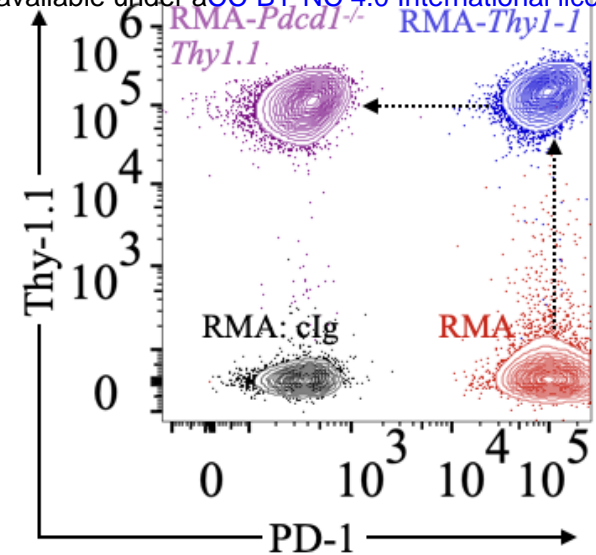

B no tumor +RMA no tumor +RMA no tumor +RMA

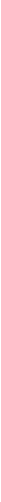

Gate on: NK cells

$\mathrm{CD}^{+} \mathrm{T}$ cells

B cells

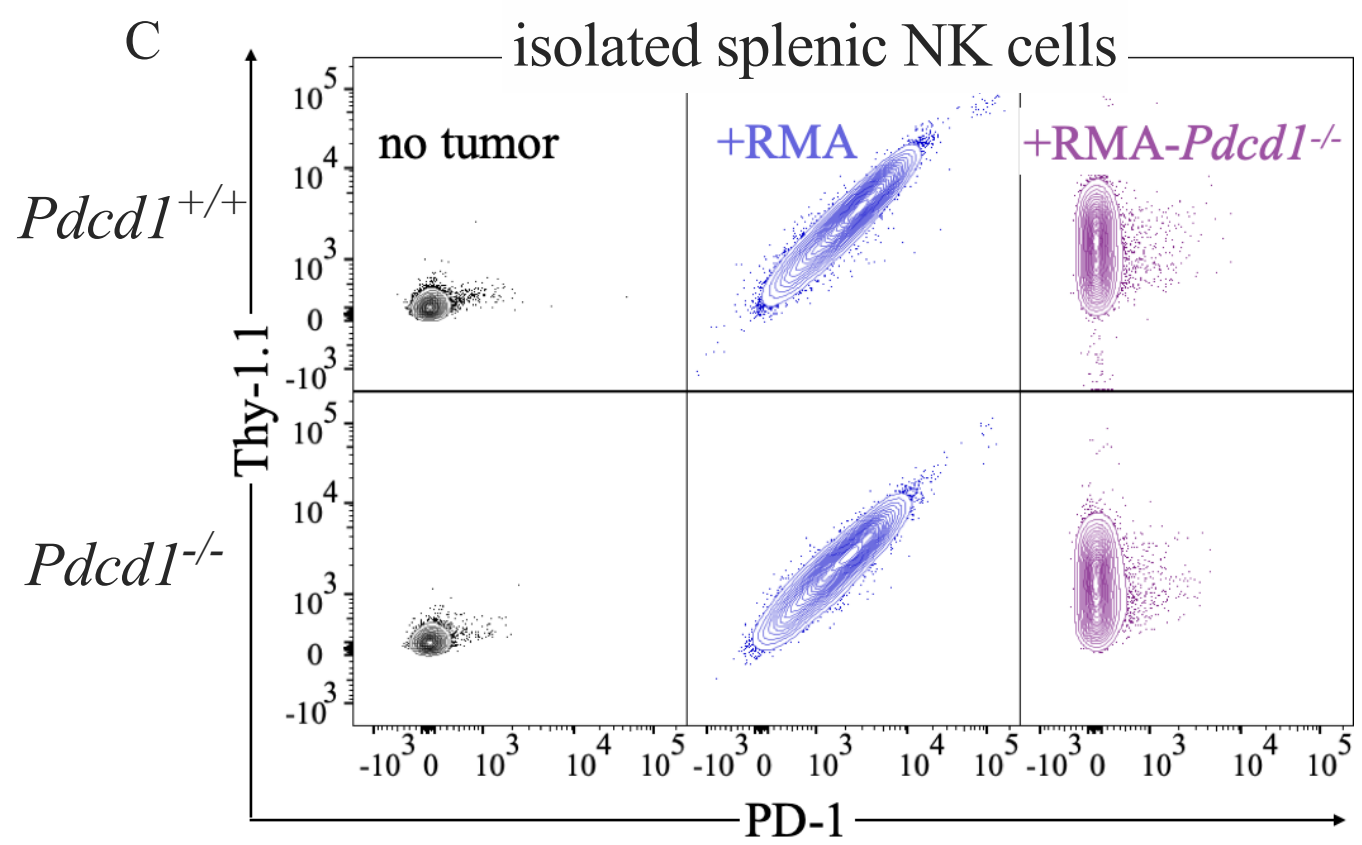


bioxiviv preprint doi: https://doi.org/10.1101/2020.06.26.174342; this version posted March 30,2021 . The copyright holder for this pr
(which was not certifified by peer review) is the autherffunder, who has granted bioRxiv a license to display the preprint in perpetuity. It

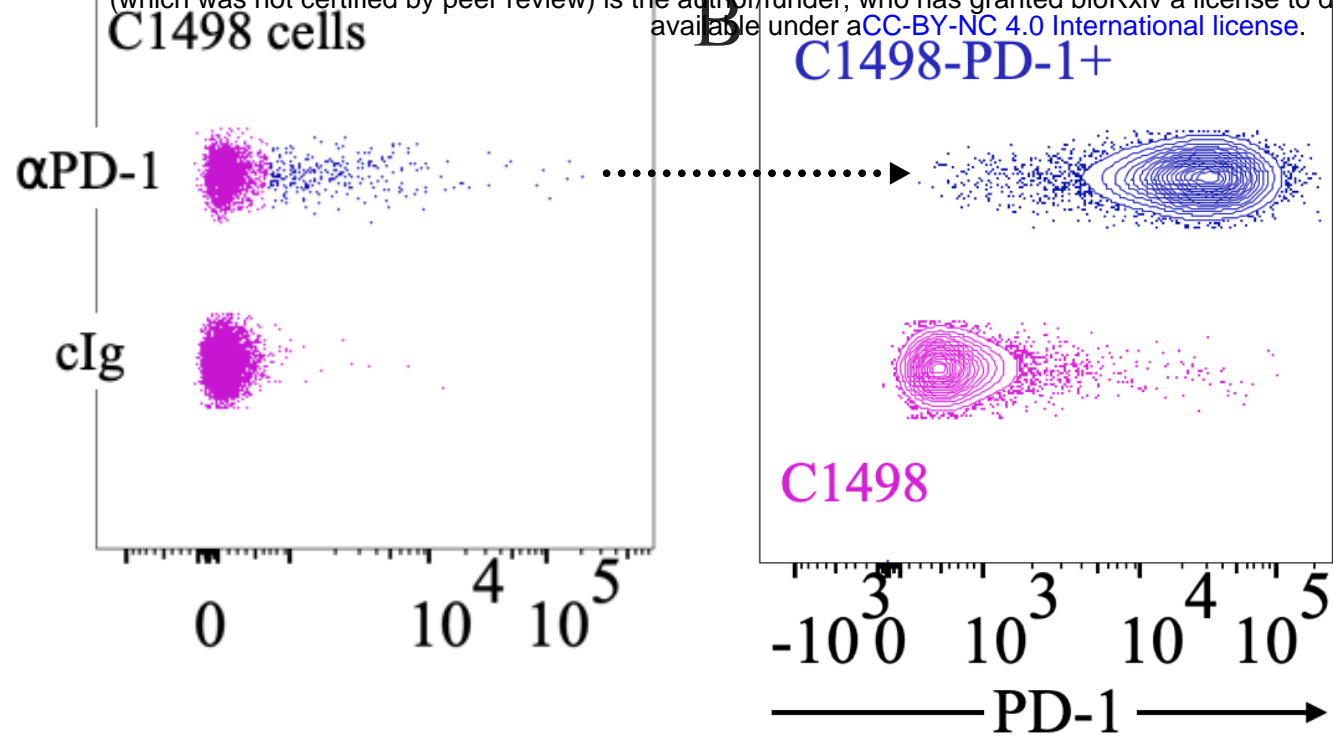

\section{Gate on: NK cells $\quad \mathrm{CD}^{+} \mathrm{T}$ cells}

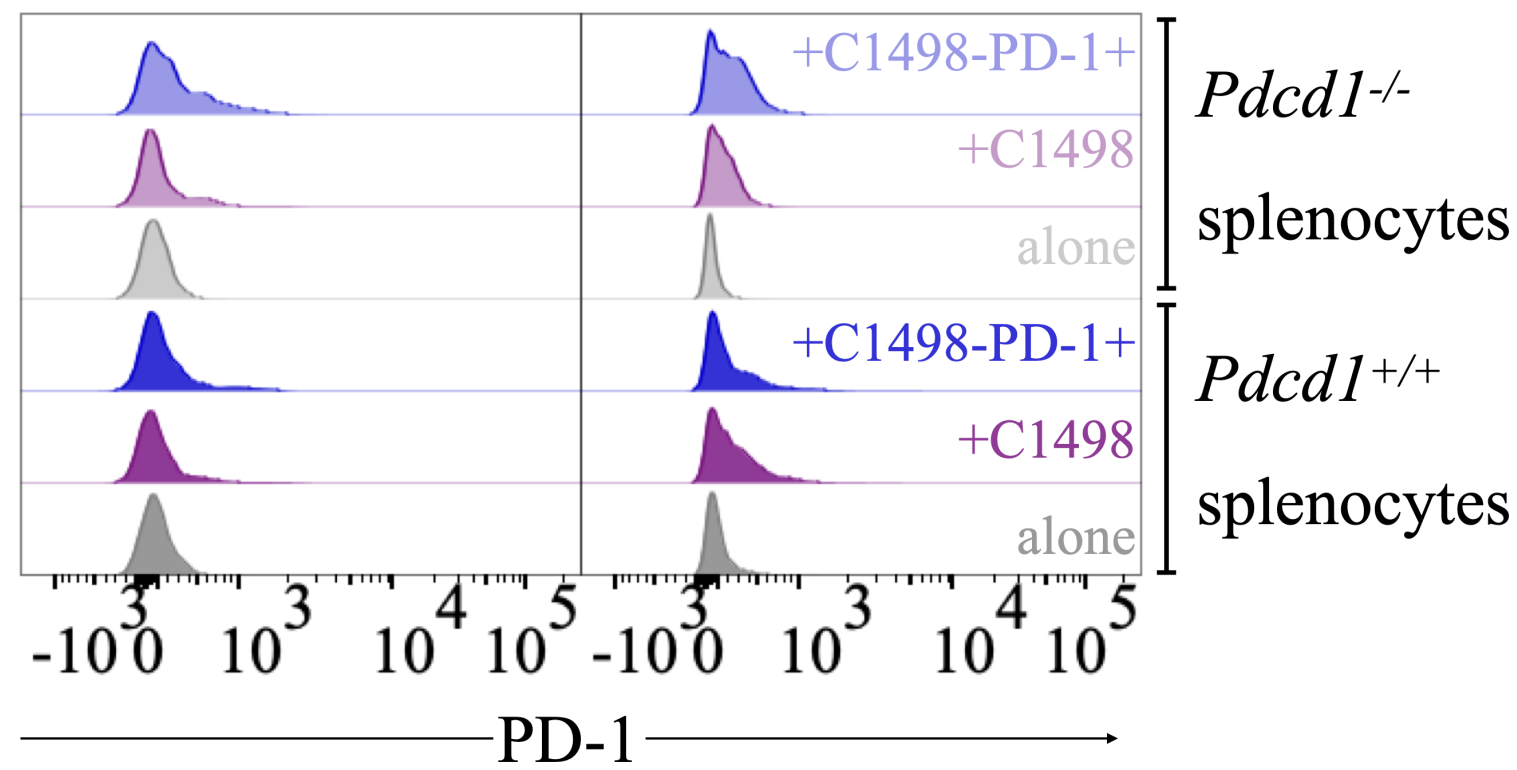

D $\quad P d c d 1^{-/} \mathrm{NK}$ cells +

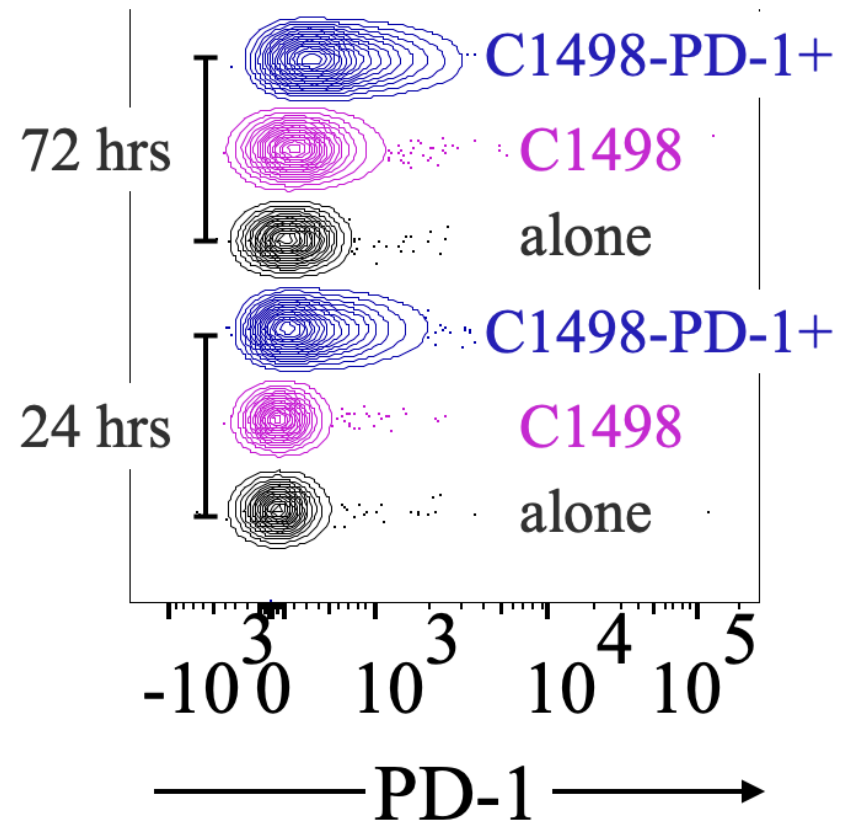



available under aCC-BY-NC 4.0 Bernational liceddK cells+
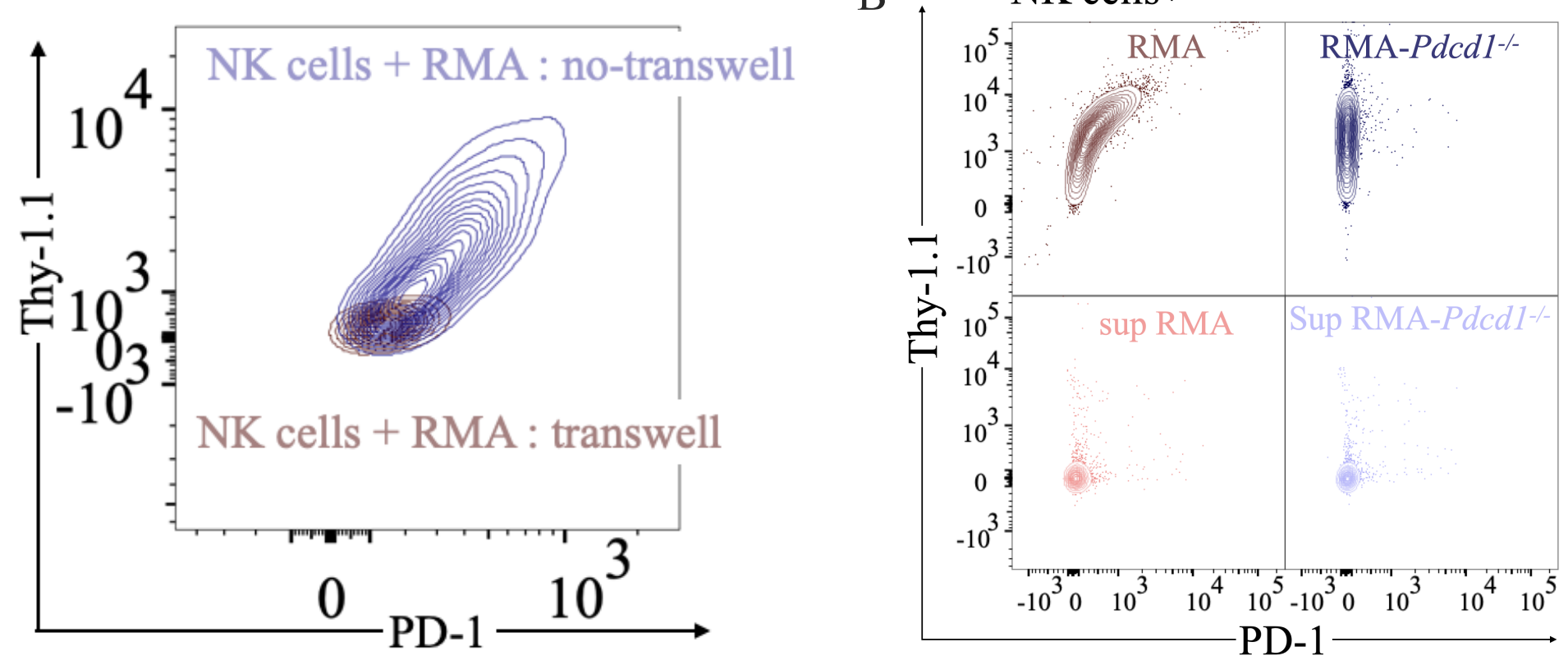

C
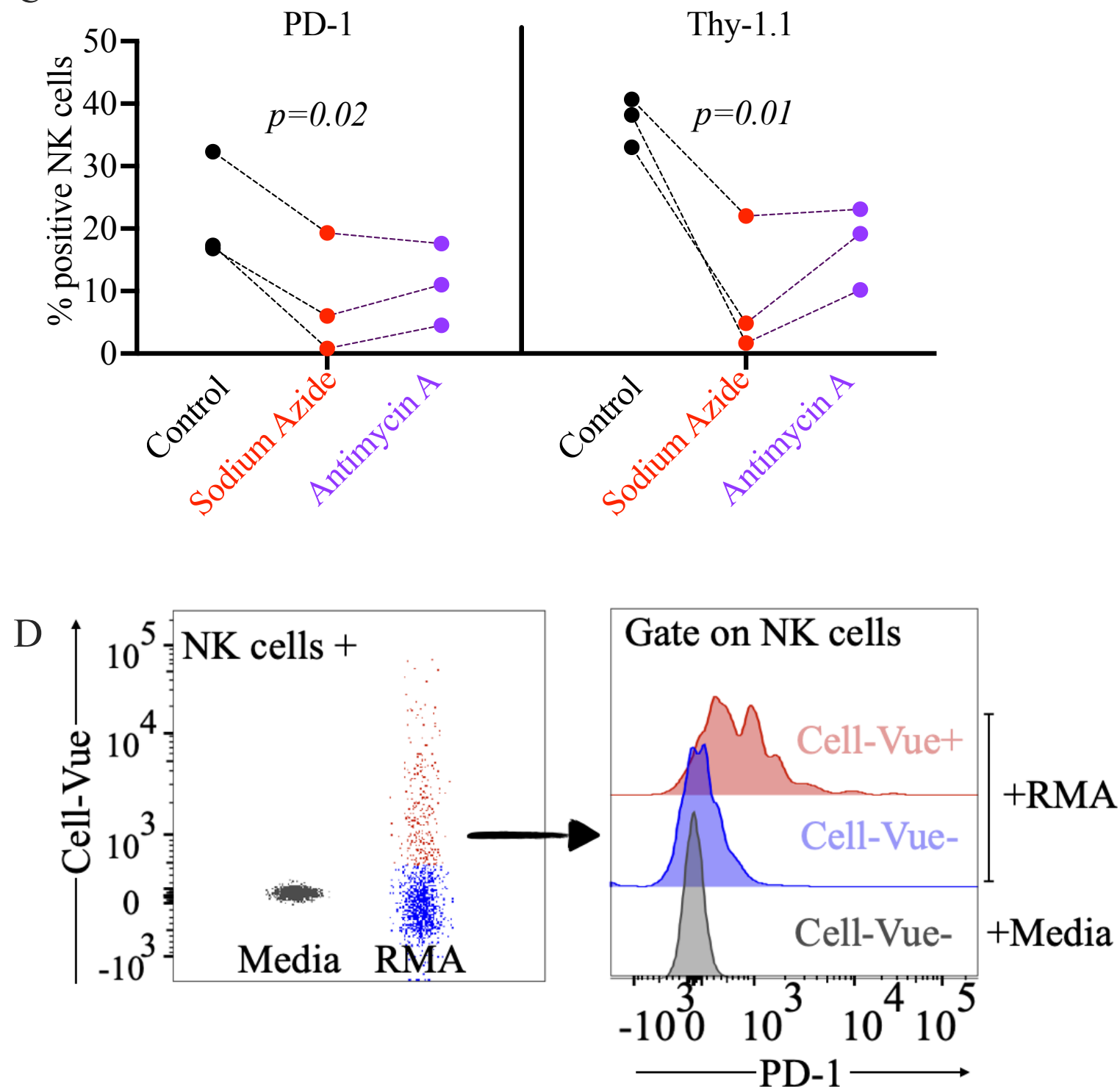

Figure 3 
(which was not certified by peer review) is the author/funder, who has granted bioRxiv a license to display the preprint in perpetuity. It is made

A Isolated NK cells + IL-2

available under aCC-BBNC 4.0NKKr

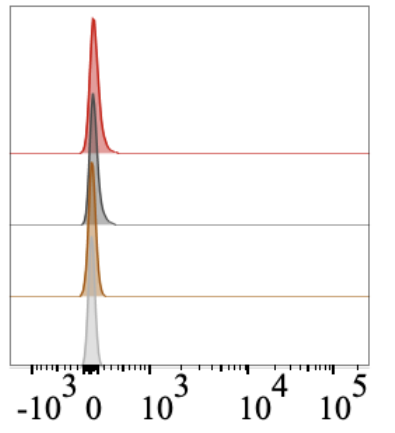

PD-L2 $\longrightarrow$

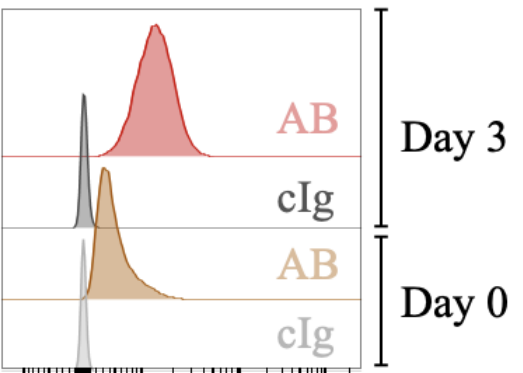

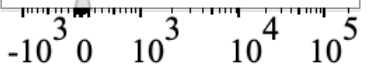

PD-L1 $\longrightarrow$

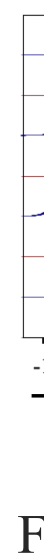

F
NK cells isolated from $P d c d 1^{-/-N c r} 1^{+/ C r e} C d 274 f / f l$

D

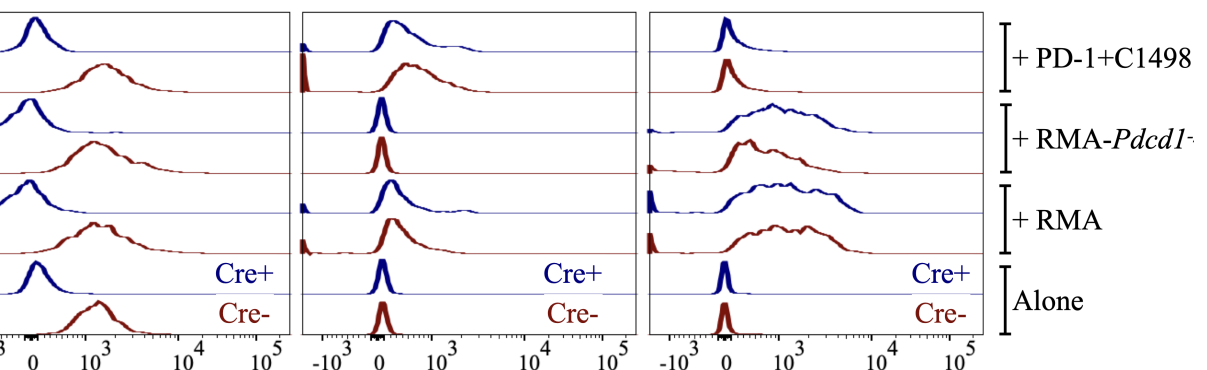

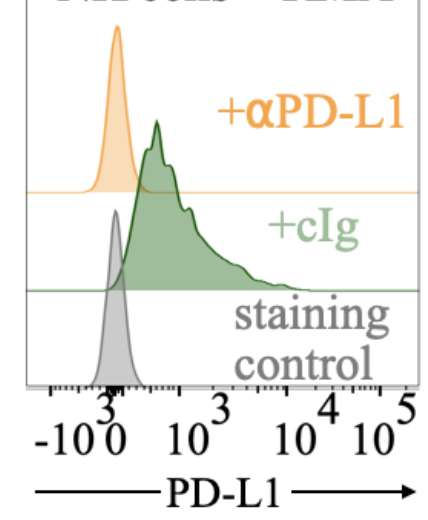

NK cells isolated:

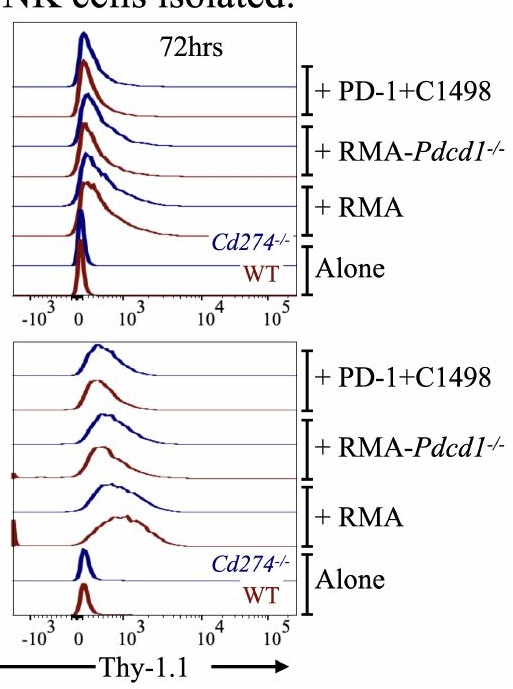

Splenic NK cells:

\section{SLAM-KO}

SLAM-KO

SLAM-KंO

WT

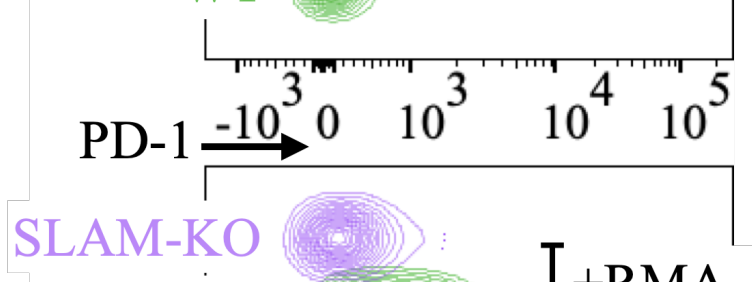

SLAM-KO

SLAM-KंO

SLAM-KंO

WT

I+RMA-Pdcd1-/-

WT

I+RMA

IAlone
E

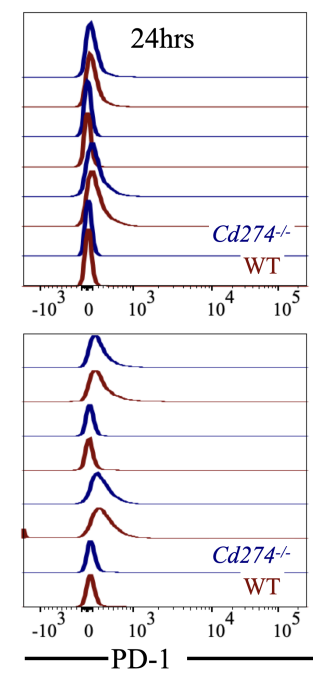

G

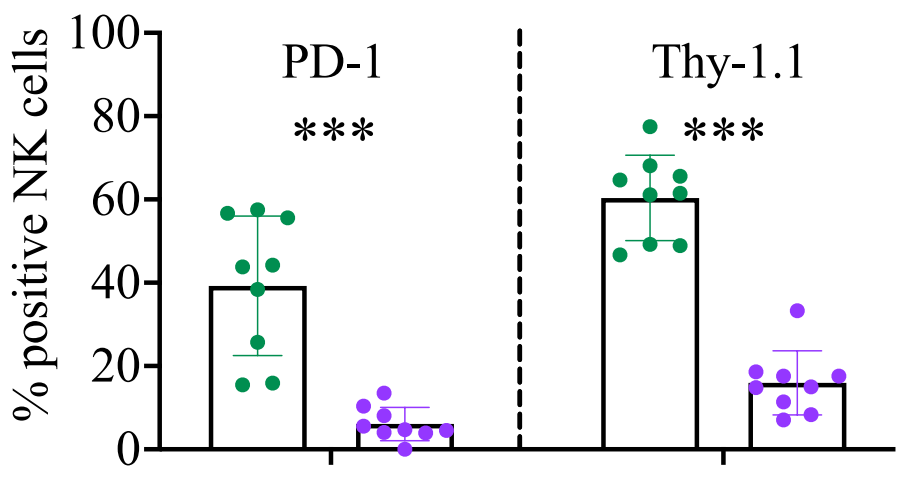

$\mathrm{H}$

\section{WT SLAM-KO WT SLAM-KO}

Splenic NK cells:

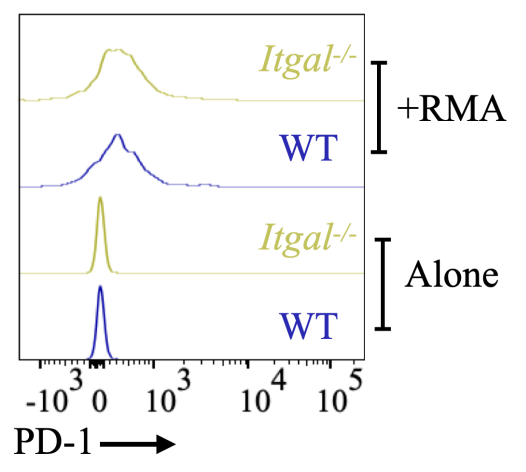

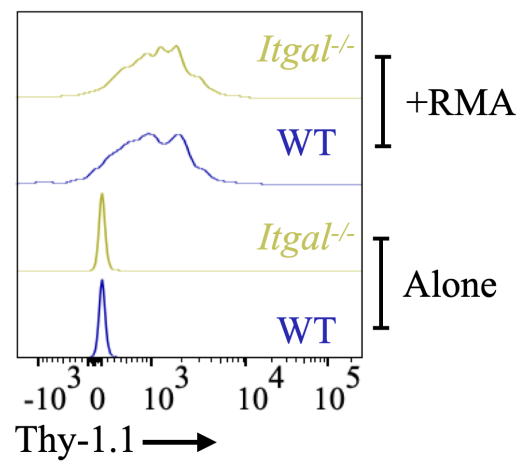

Figure 4 

bioRxiv preprint doi: https://doi.org/10.1101/2020.06.26.174342; this version posted March 30, 2021. The copyright holder for this preprint
A (which was not certified by peer review) is the author/funder, who $\mathrm{h}$ g granted bioRxiv a license to display the preprint in perpetuity. It is made available under aCC-BY-NC 4.0 International license.

\section{control isotype}
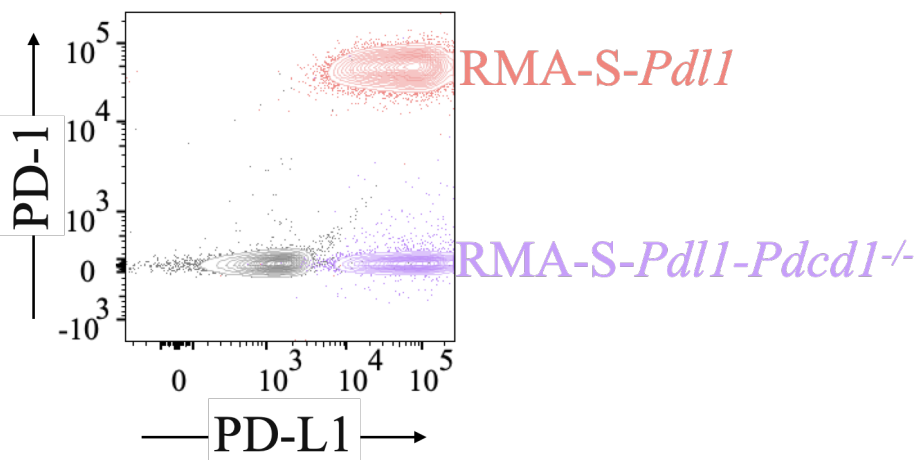

$\mathrm{C}$

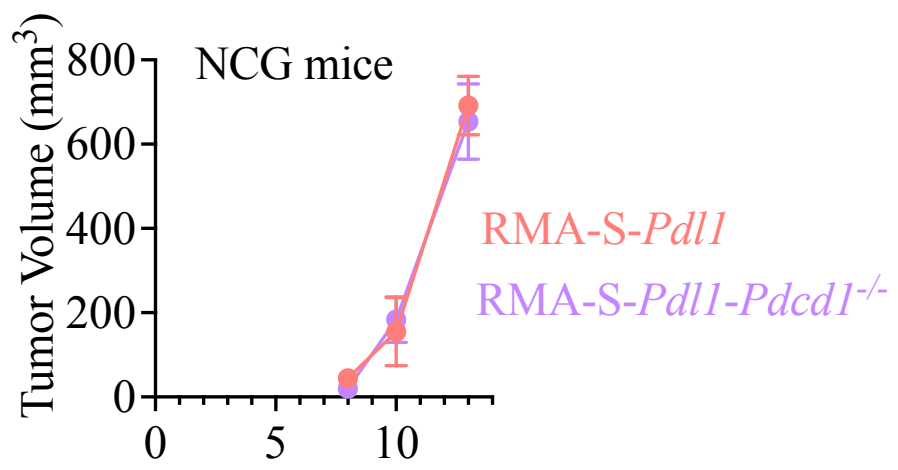

days after tumor implantation

$\mathrm{E}$

हُ

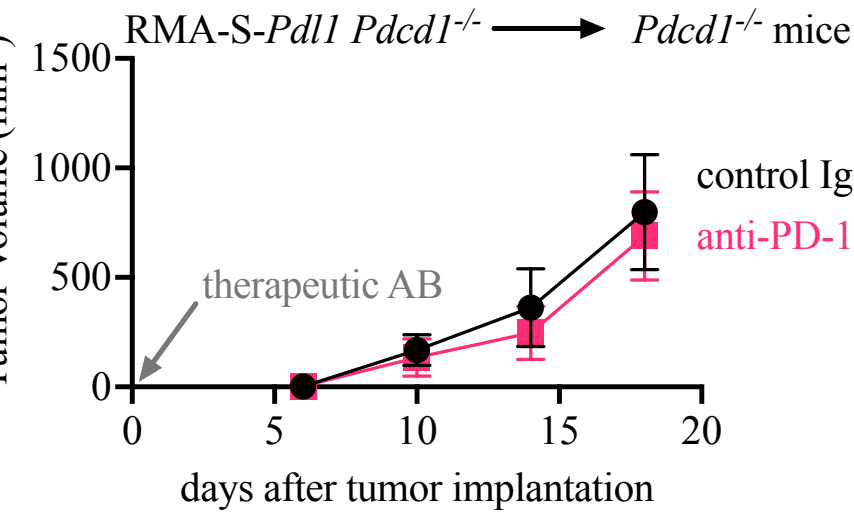

$\mathrm{G}$

?
?

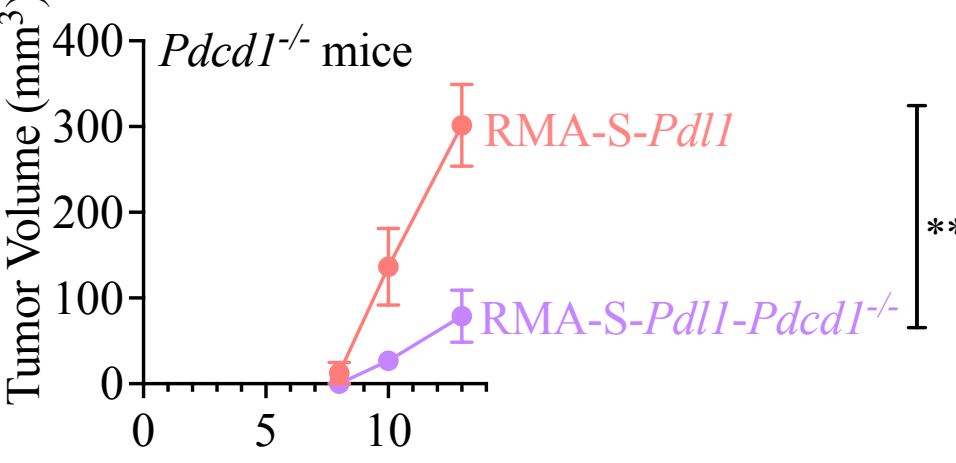

days after tumor implantation

$\mathrm{D}$

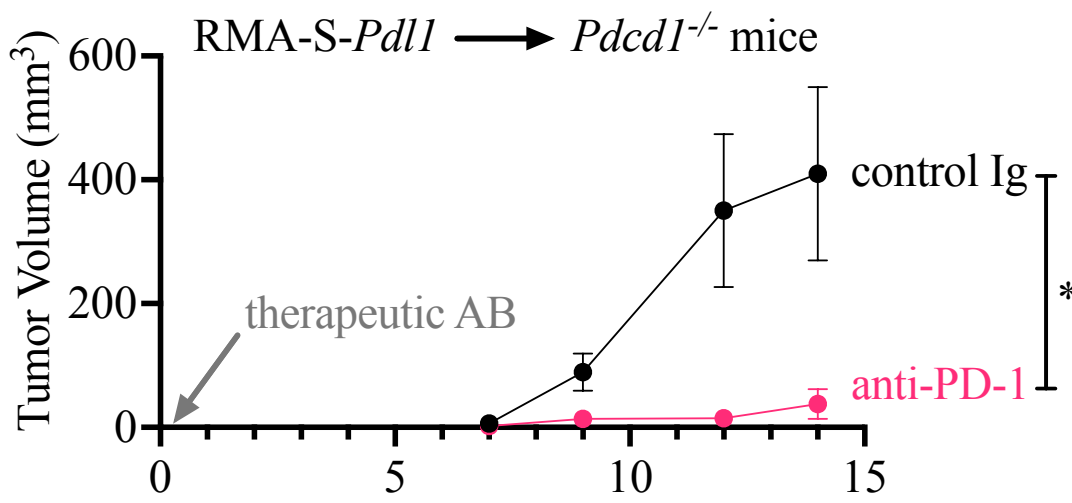

days after tumor implantation

F

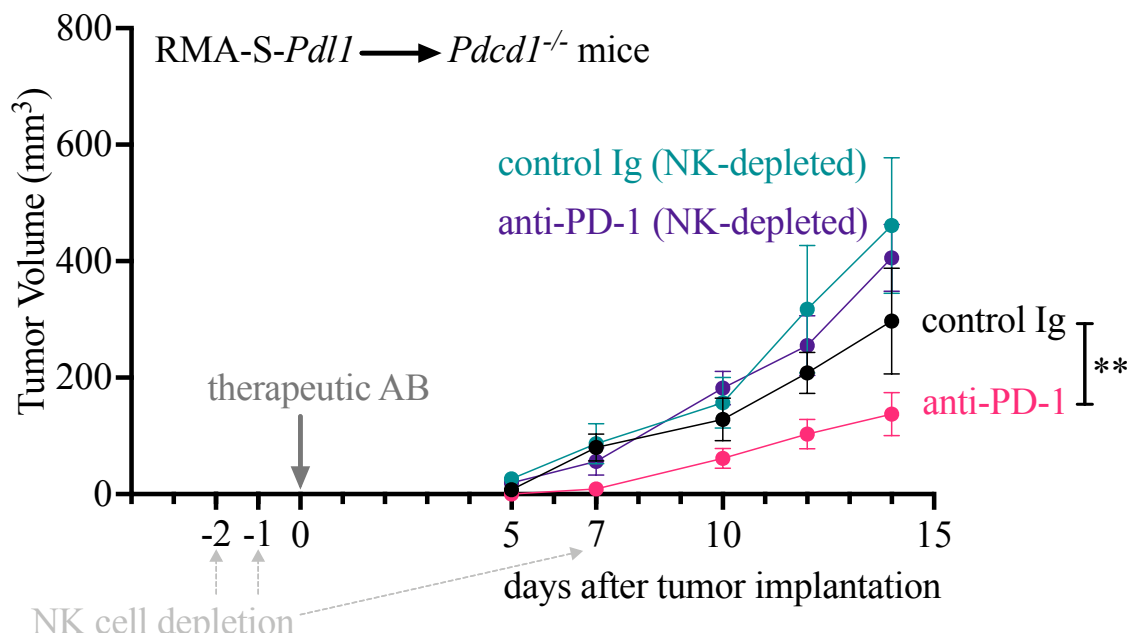

$\mathrm{H}$

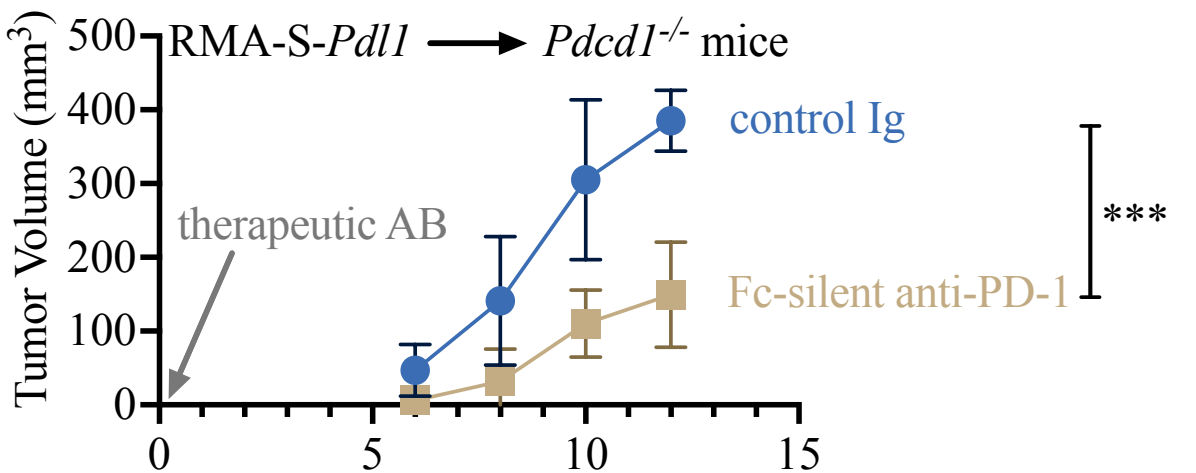

Figure 6 


\section{BM aspirates}

A

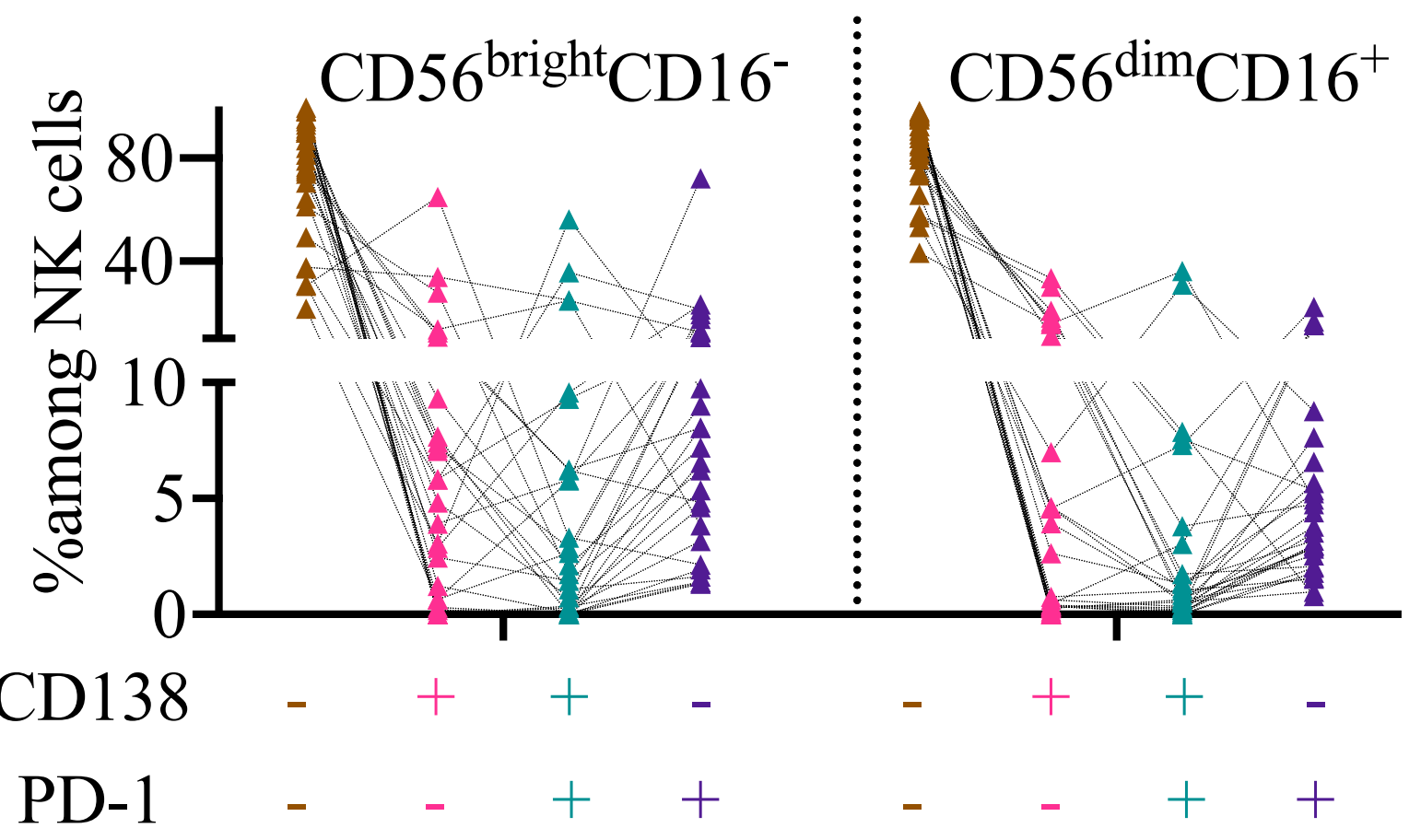

Figure 7 
Splenic NK cells +
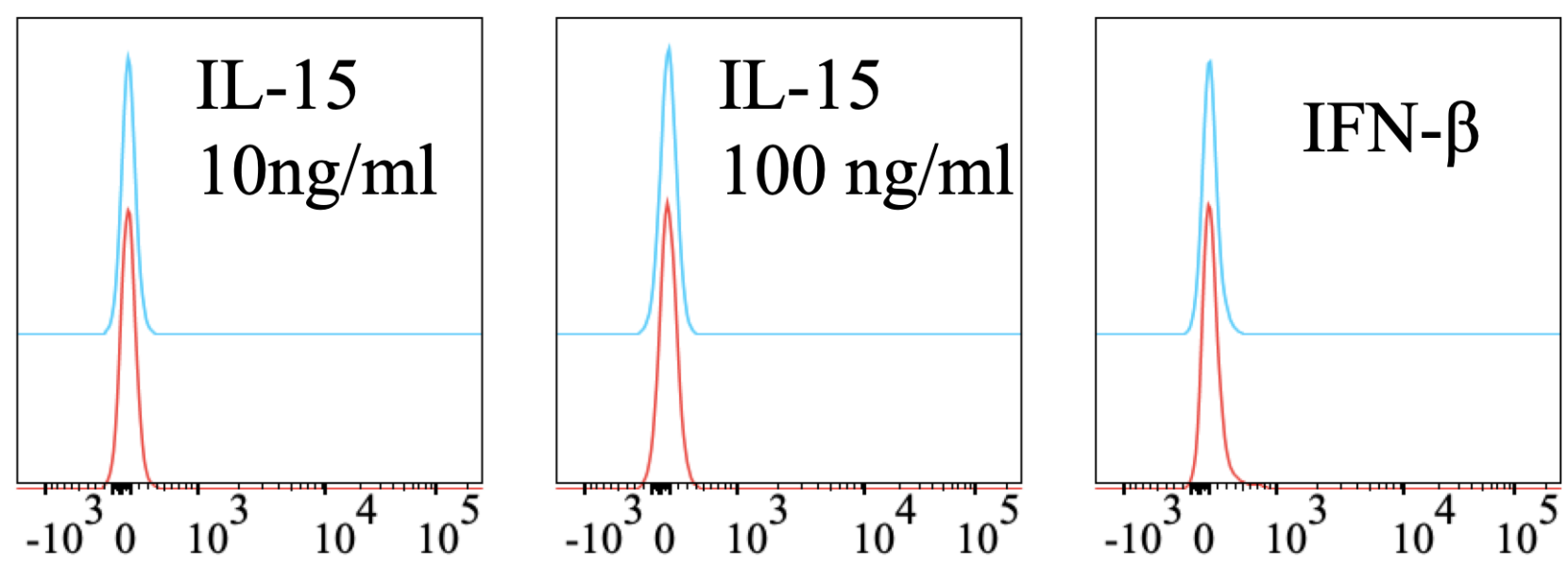

Pdcd1-/

$P d c d 1^{+/+}$
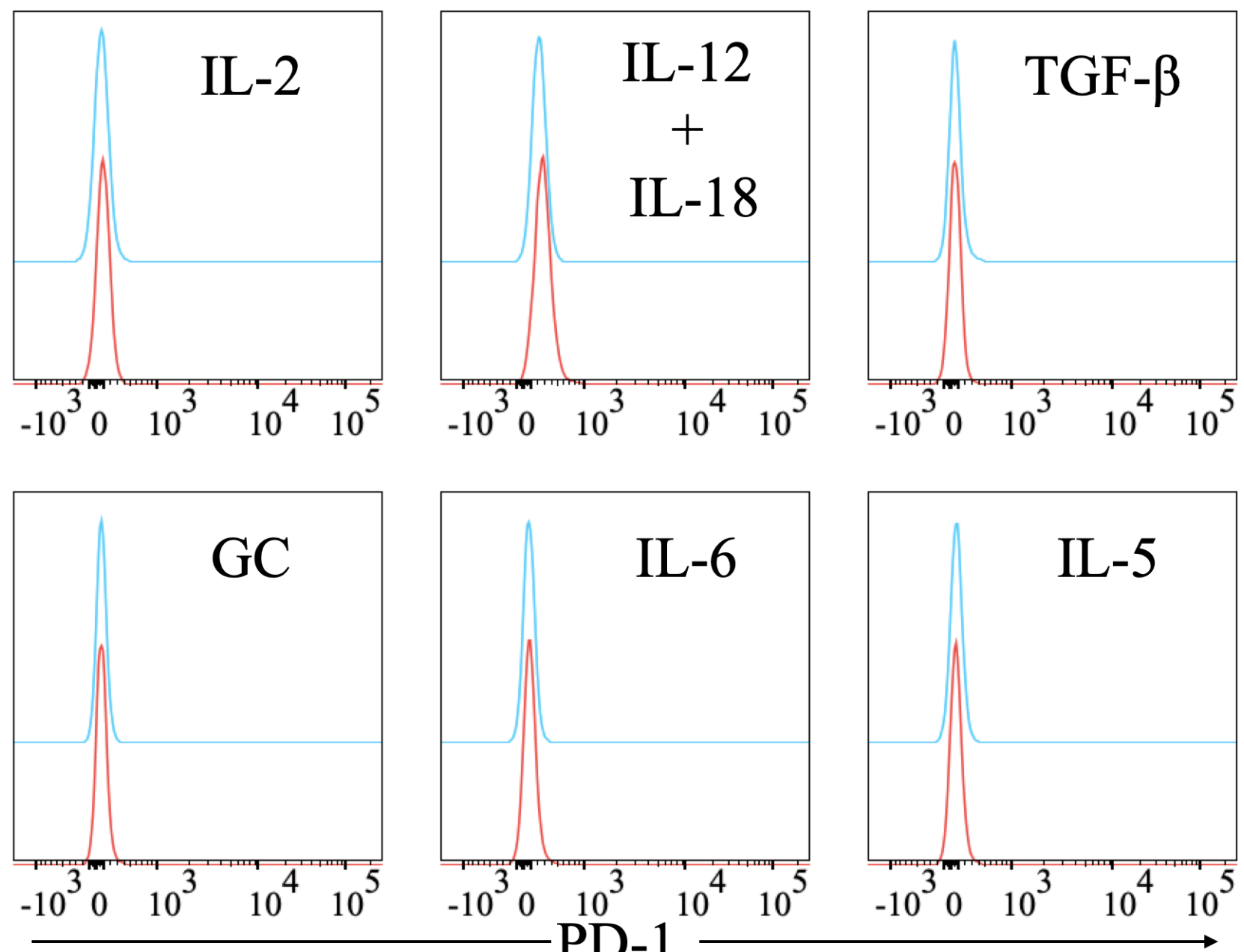

Supplementary Figure 1 
A

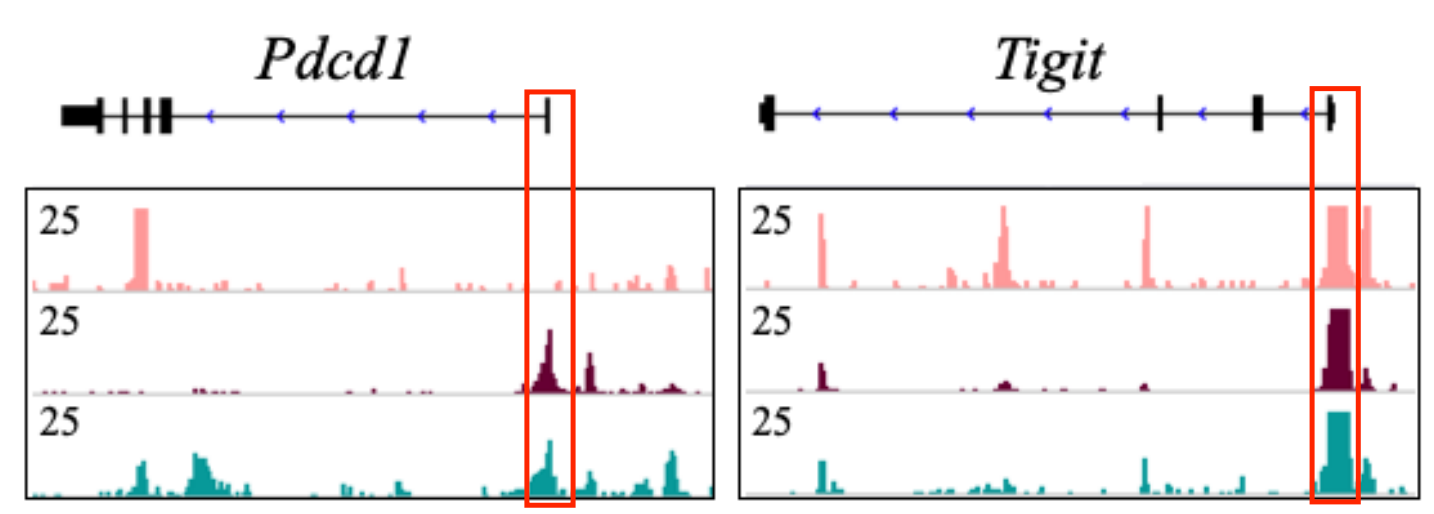

B
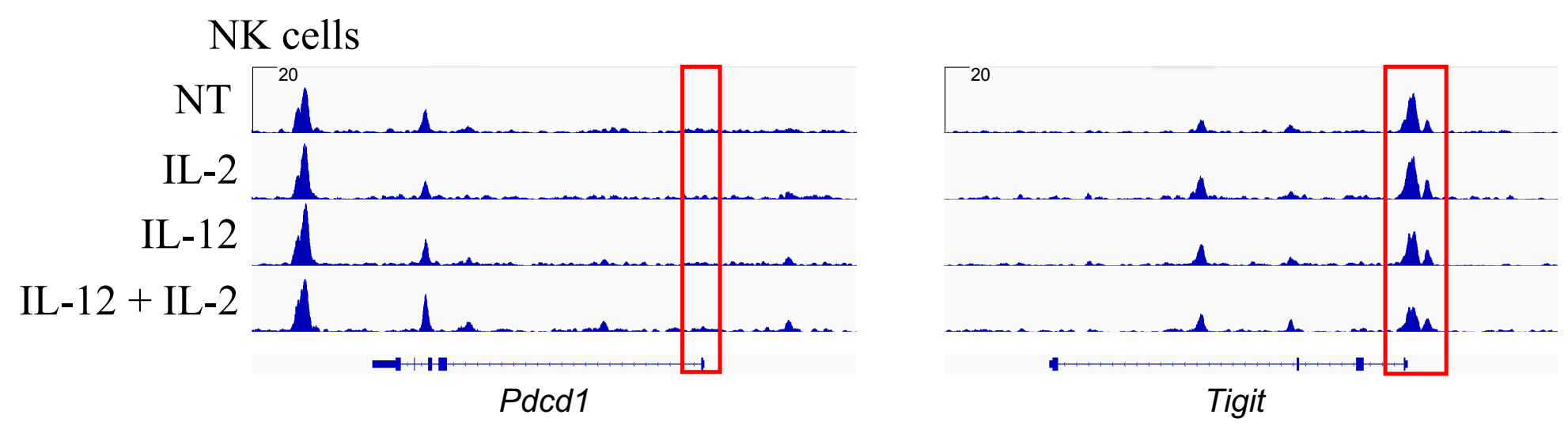

Supplementary Figure 2 


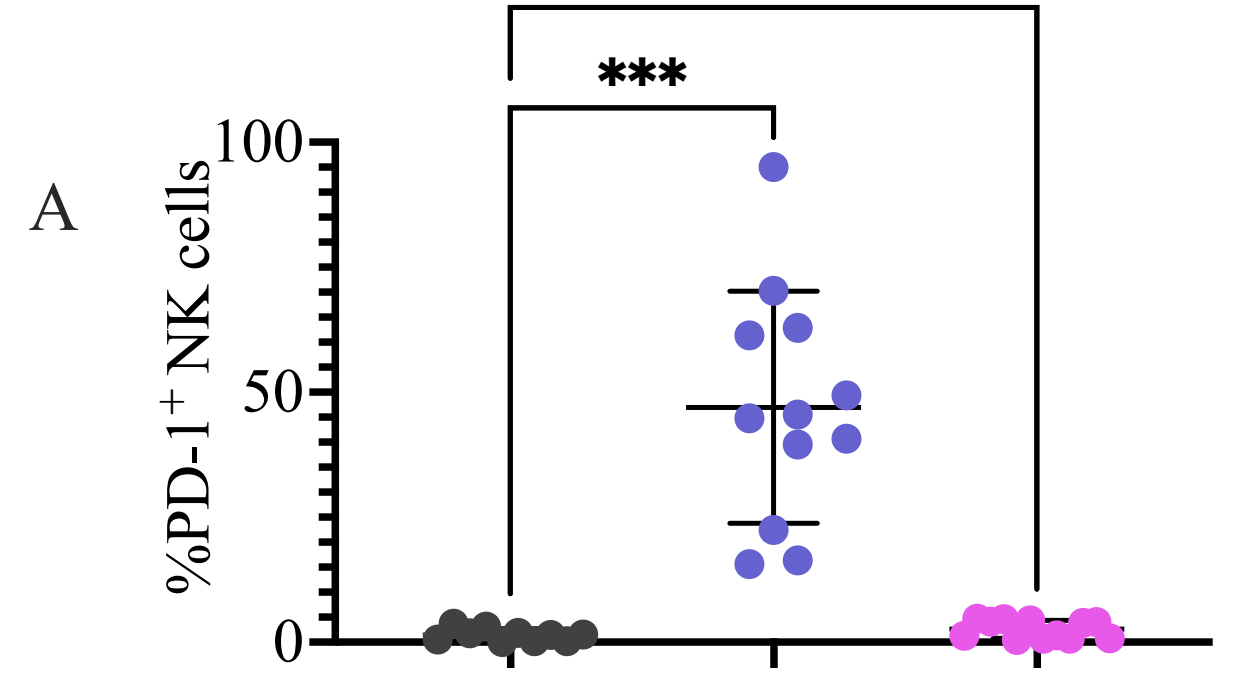

Isolated splenic NK cells + media $\quad$ RMA RMA-Pdcd1--

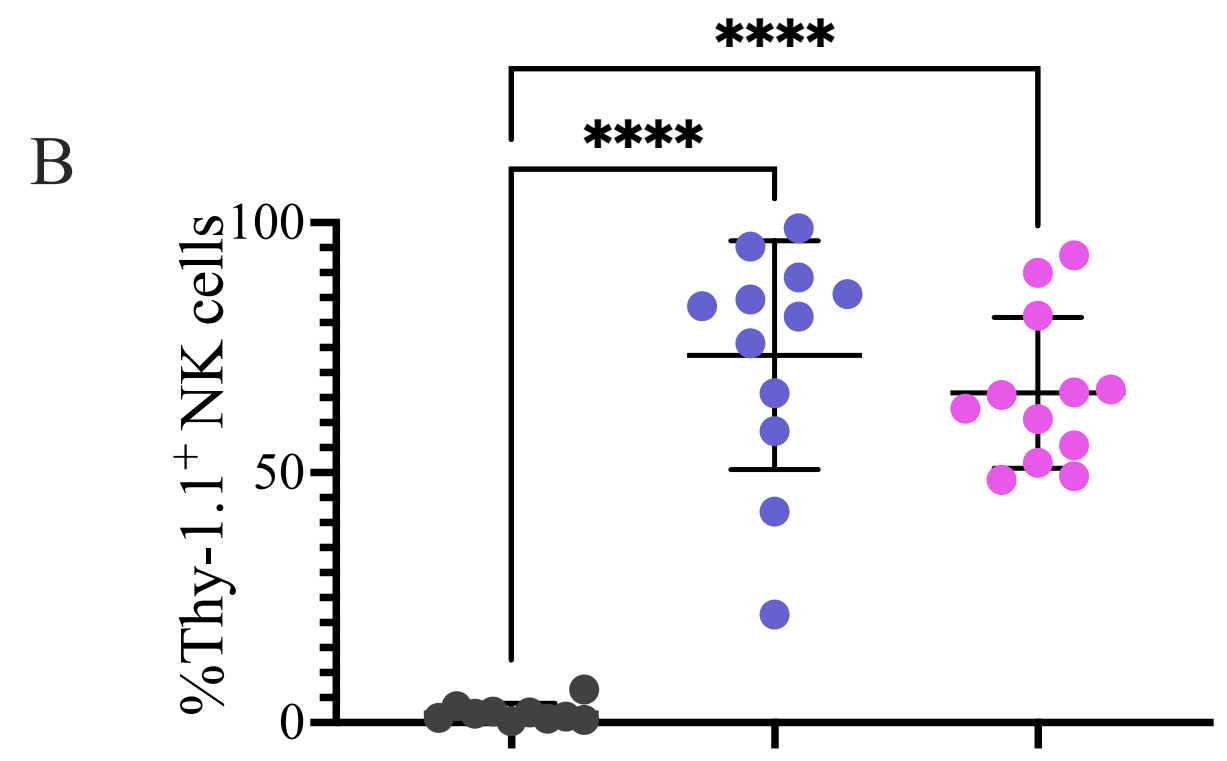

Isolated splenic NK cells + media $\quad$ RMA RMA-Pdcd1--

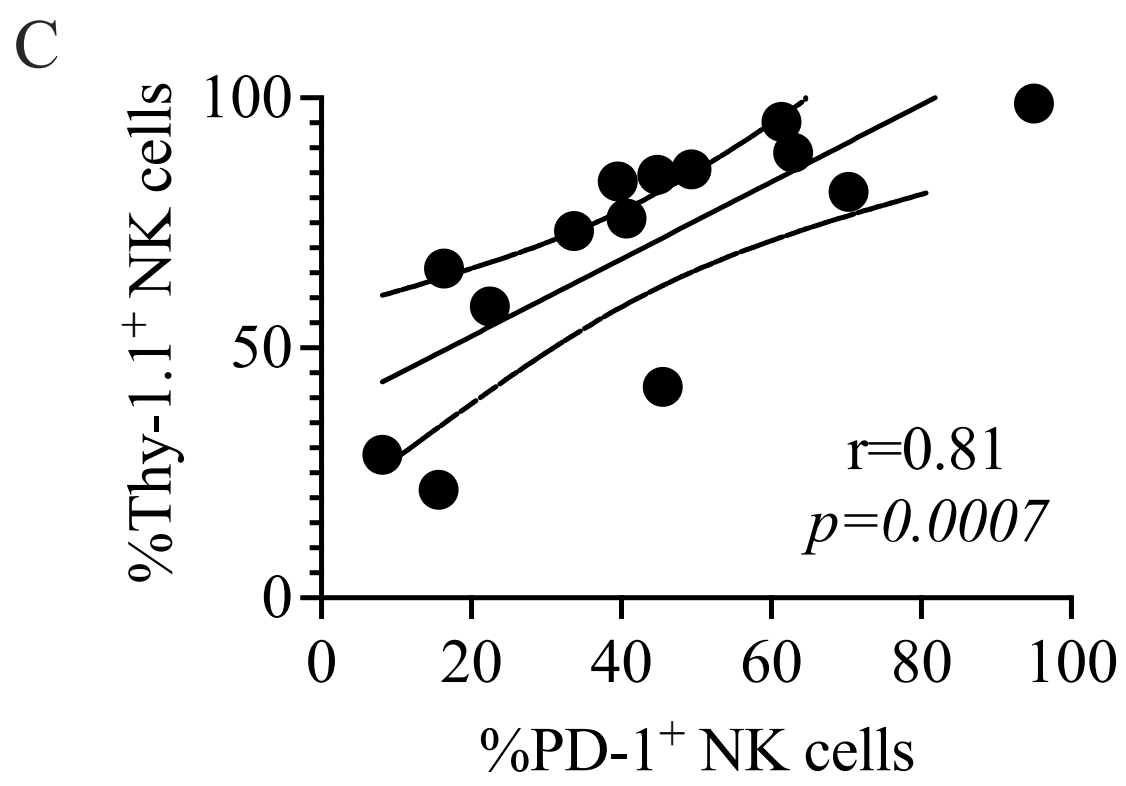

Supplementary Figure 3 
CD45.1+ isolated splenic NK cells +
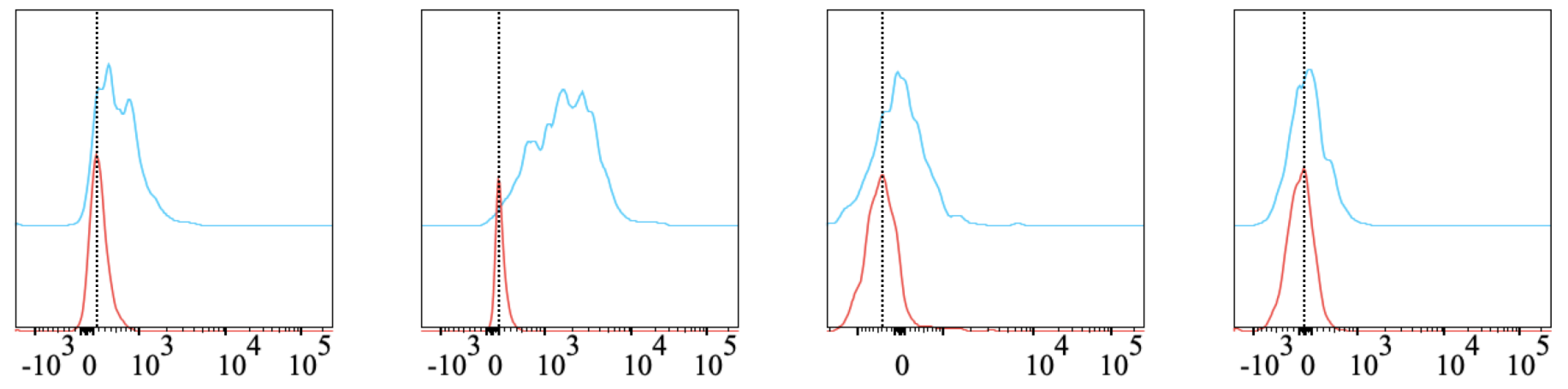

RMA

-PD-1

Thy-1.1

CD45.2

TCRv $\beta 12$

Supplementary Figure 4 
A

RMA cells: $\quad$ Blocked with: $\quad$ Stained with:

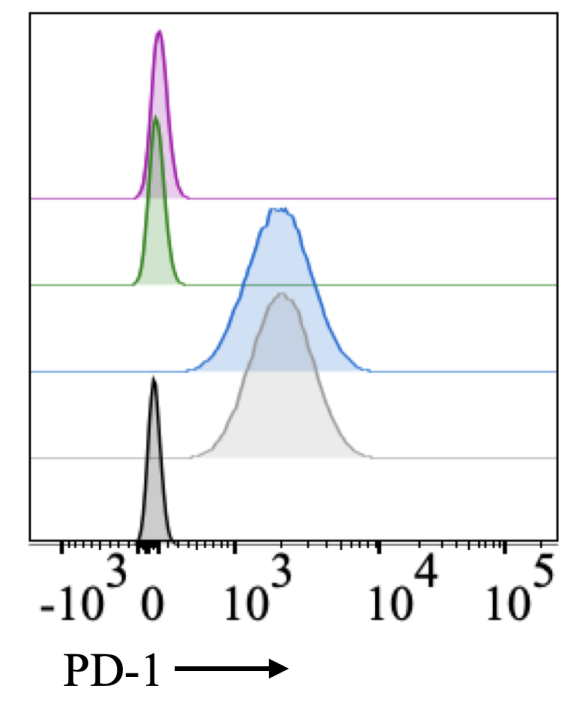

Fc-silent anti-PD-1 anti-PD-1

control isotype

\section{control isotype}

control isotype

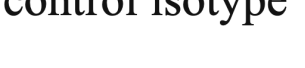

B

NK cells+RMA cells

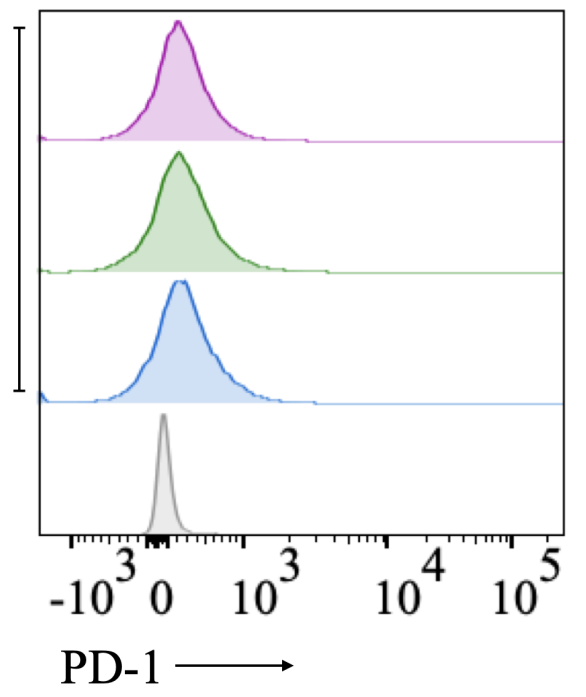

Blocked with:

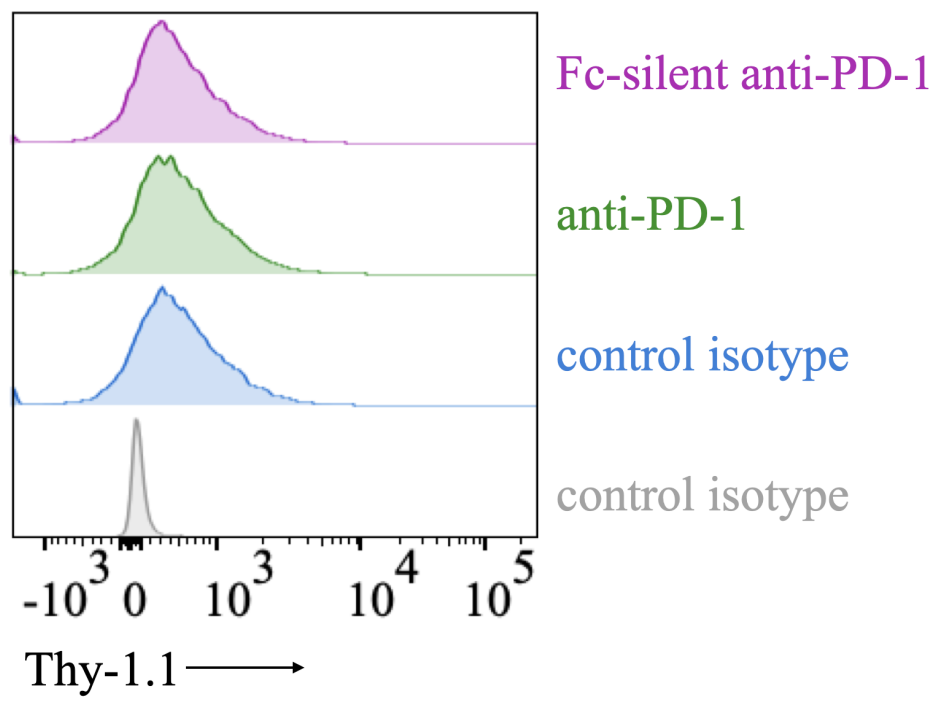

Supplementary Figure 5 
NK cells

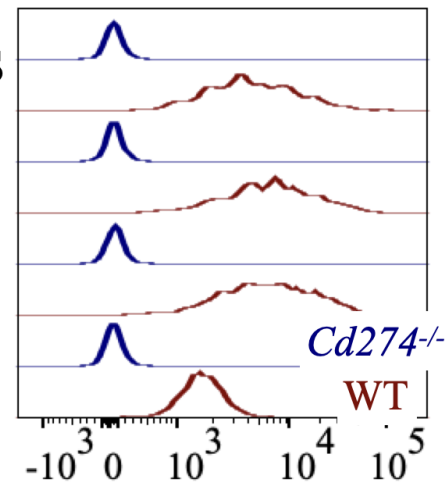

$\mathrm{CD} 8^{+}$

$\mathrm{T}$ cells

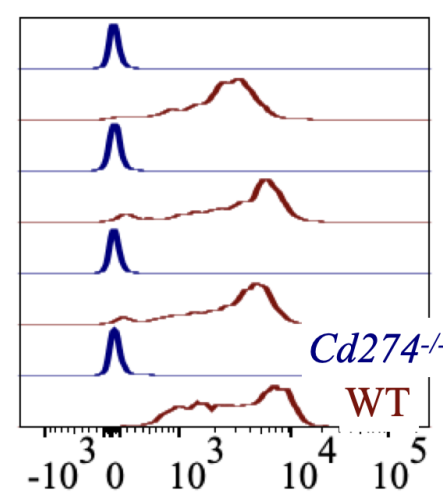

B cells

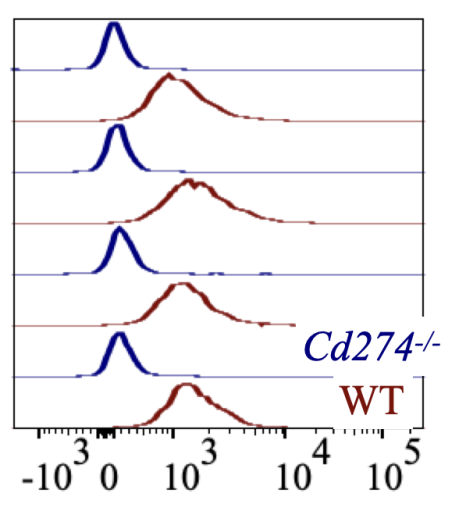

PD-L1
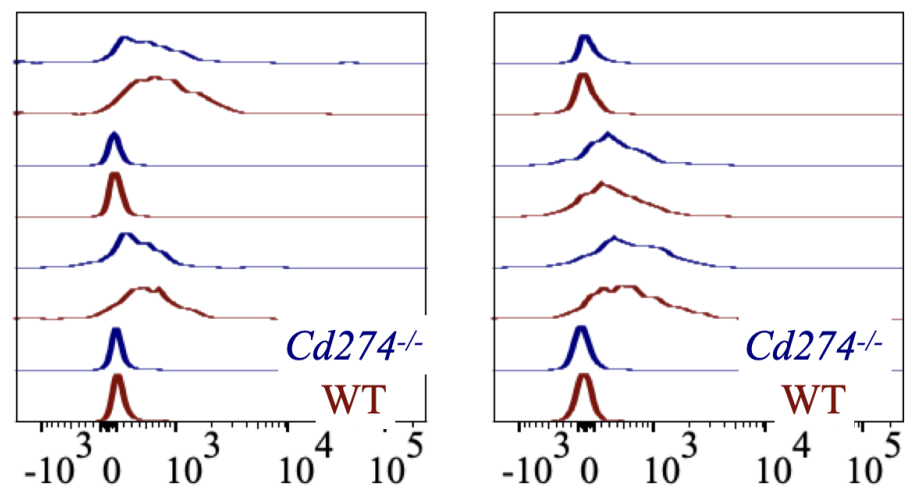

$$
\begin{aligned}
& \text { I + PD-1+C1498 } \\
& \text { I + RMA-PdcdI- } \\
& \text { I + RMA } \\
& \text { I Alone }
\end{aligned}
$$
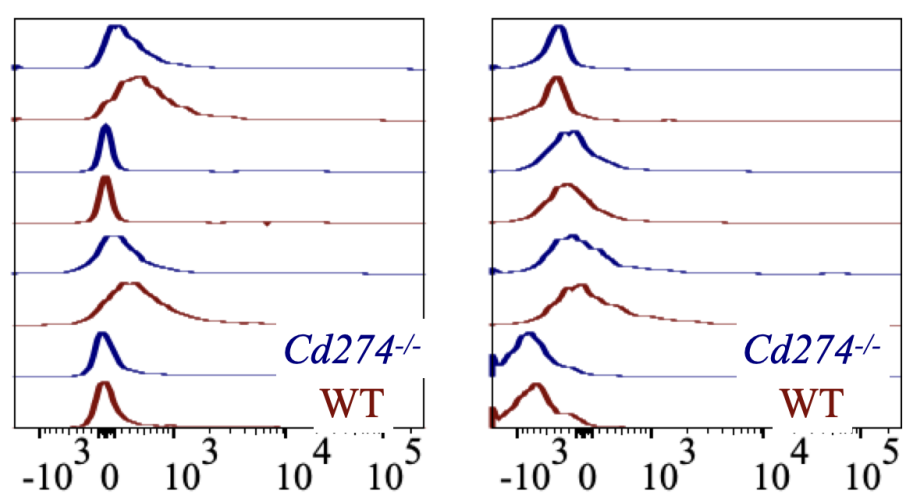

$$
\begin{aligned}
& \mathrm{I}+\mathrm{PD}-1+\mathrm{C} 1498 \\
& \mathrm{I}+\mathrm{RMA}-P d c d 1^{-/} \\
& \text {I+ RMA } \\
& \text { I Alone }
\end{aligned}
$$
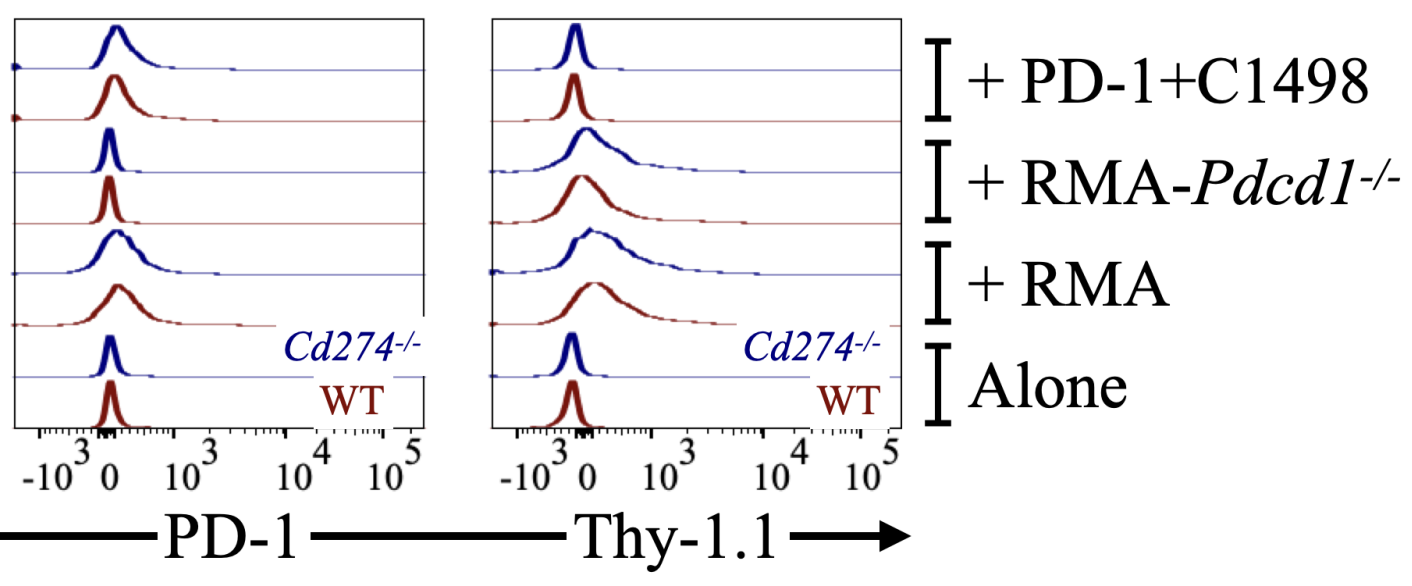
Splenic $\mathrm{CD} 8^{+} \mathrm{T}$ cells: available under aCC-BY-NC 4.0 International license.

\section{SLAM-KO}

WT

SLAM-KO

WT

SLAM-KO

WT

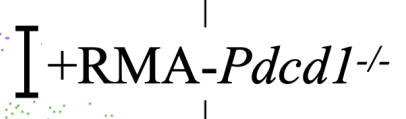

PD- $1 \stackrel{-10^{3}}{\longmapsto} 0 \quad 10^{3} \quad 10^{4} \quad 10^{5}$

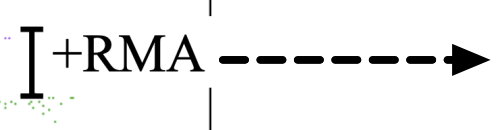

\section{SLAM-KO}

\section{WT \\ SLAM-KO}

WT

SLAM-KO

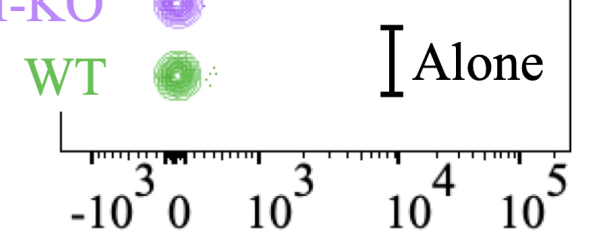

Thy-1.1 $\longrightarrow$

Splenic B cells:

$$
\text { I+RMA-Pdcd1-/- }
$$

I+RMA

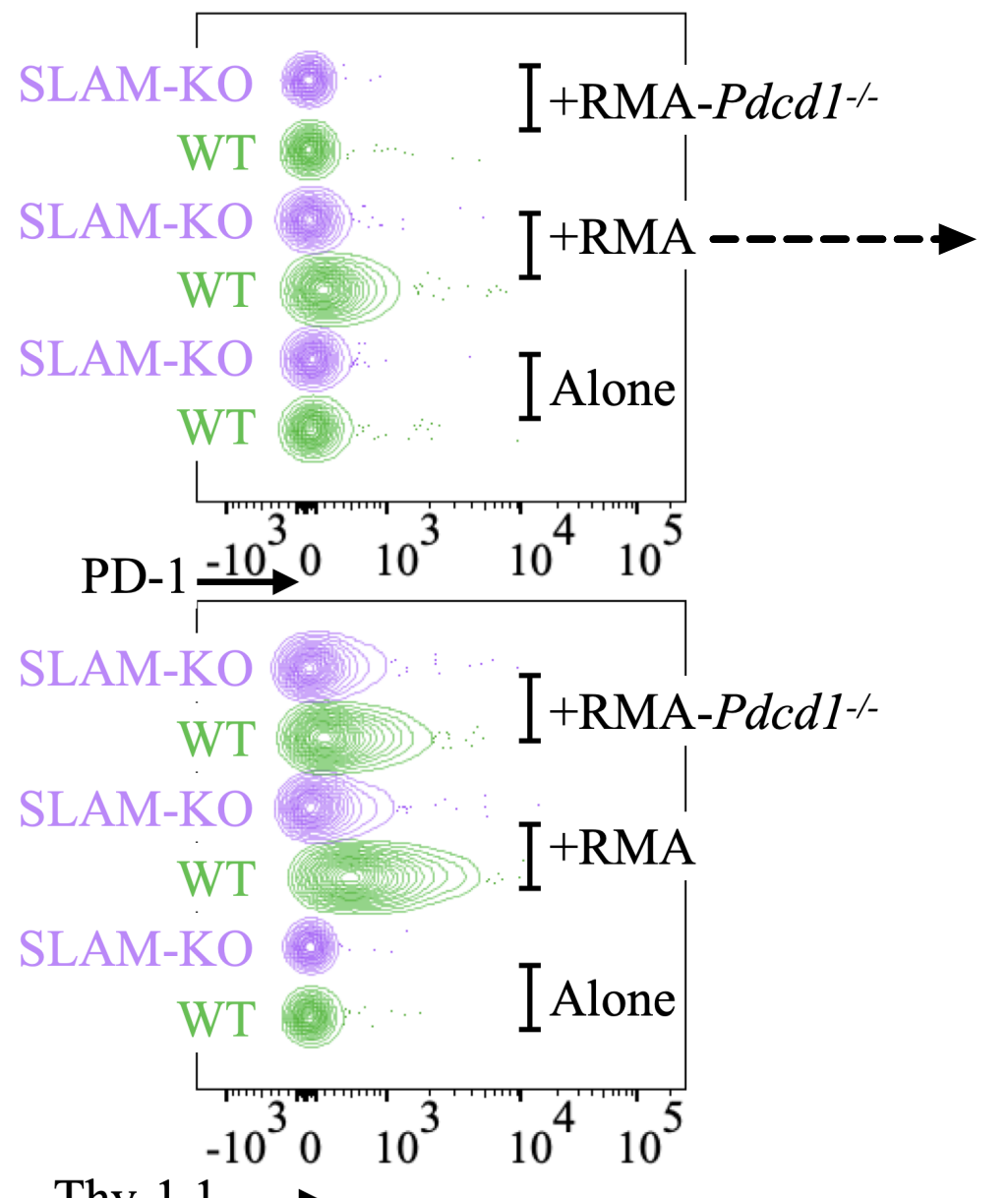

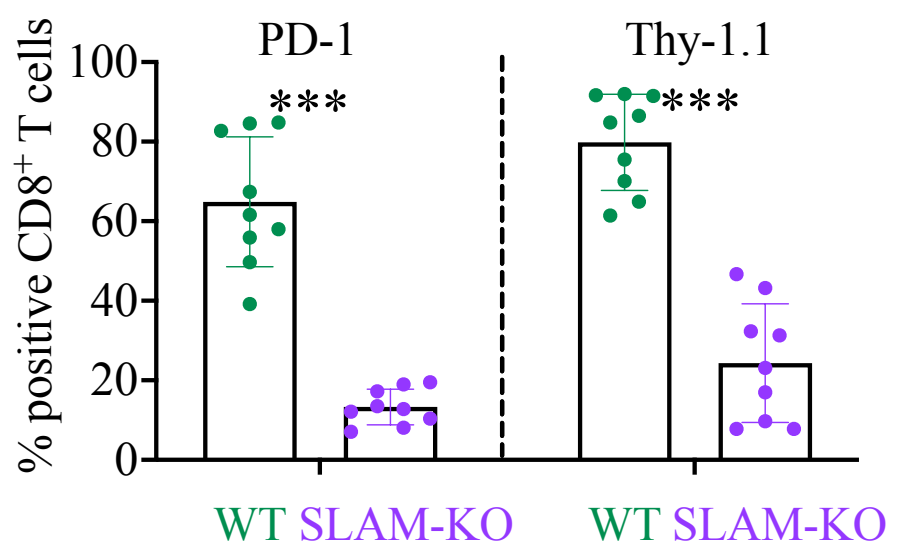

$\mathrm{D}$

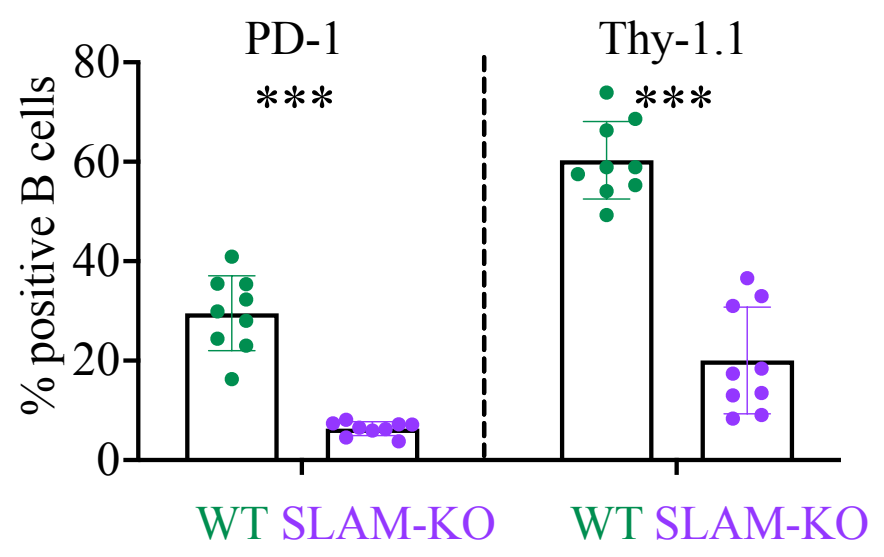




\section{Splenic $\mathrm{CD} 8^{+} \mathrm{T}$ cells: $\quad$ Splenic B cells:}
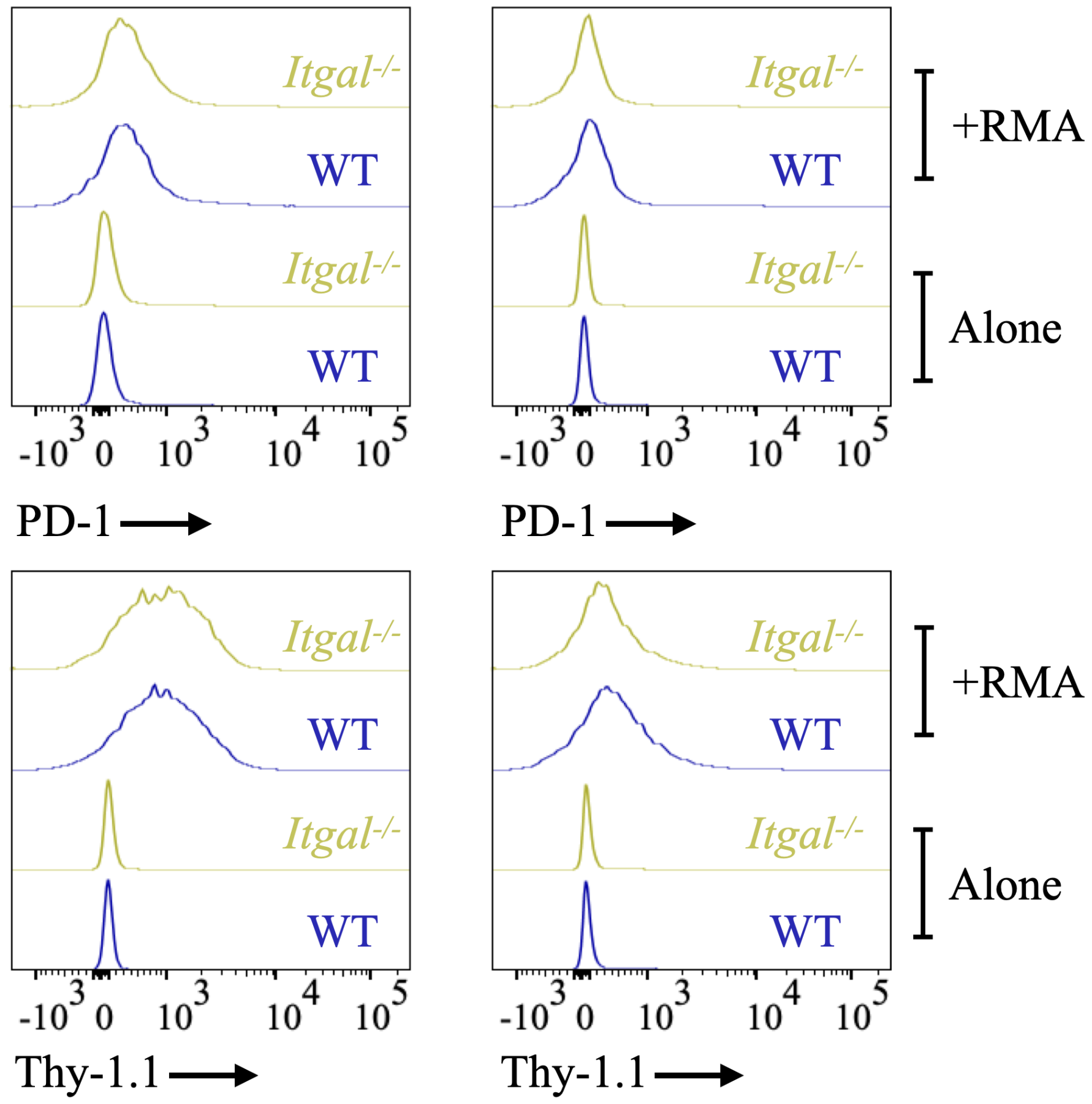

Supplementary Figure 8 


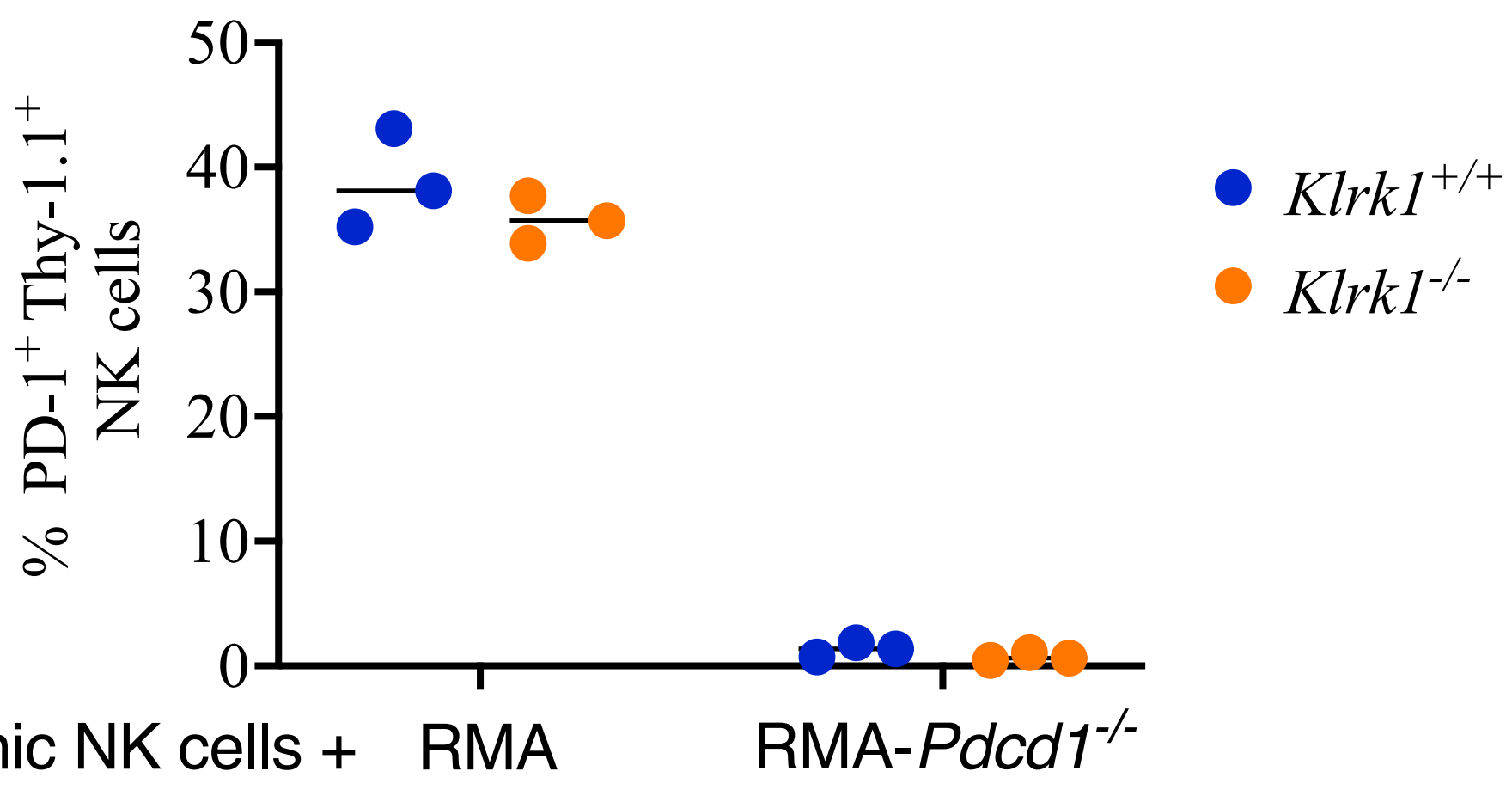
splenic NK cells + RMA RMA-Pdcd1 $1^{-1}$ 


\section{BM aspirate}

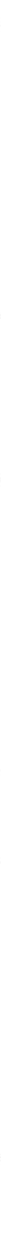

